\title{
Older people's experiences of dignity and support with eating during hospital stays: analytical framework, policies and outcomes
}

\author{
Polly Vizard ${ }^{1 \star}$ (D) and Tania Burchardt ${ }^{1}$ \\ ${ }^{1}$ Centre for Analysis of Social Exclusion, London School of Economics, London, UK \\ ${ }^{*}$ Corresponding author. Email: p.a.vizard@lse.ac.uk
}

(Accepted 4 March 2021)

\begin{abstract}
There is growing recognition of the importance of dignity and support with eating as markers of high-quality and older-person-centred hospital services. We use data on these markers from the national Adult Inpatient Survey for England to build up statistical evidence on older people's experiences. We find that poor and inconsistent experiences of being treated with dignity and respect, and of receiving support with eating, affect a substantial proportion of inpatients across the vast majority of acute hospital trusts. There has been remarkably little change over time, although small improvements provide some grounds for optimism relating to policy developments in the period following the Francis Inquiry. Amongst people over 65, the prevalence of inconsistent and poor experiences of dignity and support with eating was higher amongst the 'oldest of the old' (inpatients aged over 80), individuals who experience a long-standing limiting illness or disability, and women. The highest rates of prevalence were observed amongst disabled women over 80 . Perceptions of inadequate nursing quantity and quality, and lack of choice of food, stand out from logistic regression analysis as having consistent, large associations with lack of support with eating. These factors provide potential policy levers since they are within the control of hospitals to a certain extent. In drawing lessons from our analysis for inspection, regulation and monitoring, we highlight the importance of inequalities analysis - including systematic disaggregation and separate identification of at risk sub-groups (e.g. older disabled women) - rather than relying on a 'population average approach'.
\end{abstract}

Keywords: healthy ageing; capabilities; dignity; nutrition; social support; health care

\section{Introduction}

The importance of dignity and support with eating as key markers of high-quality and older-person-centred hospital and long-term care services is increasingly recognised in England and internationally. The World Health Organization's (WHO: 2015a: 127) World Report on Ageing and Health incorporates dignity

(c) The Author(s), 2021. Published by Cambridge University Press. This is an Open Access article, distributed under the terms of the Creative Commons Attribution licence (http://creativecommons.org/licenses/by/4.0/), which permits unrestricted re-use, distribution, and reproduction in any medium, provided the original work is properly cited. 
into its definition of long-term care: ' $[t]$ he activities undertaken by others to ensure that people with or at risk of a significant ongoing loss of intrinsic capacity can maintain a level of functional ability consistent with their basic rights, fundamental freedoms and human dignity'. In the English context, the Royal College of Nursing (2008) defines 'dignity in care' as person-centred care that treats individuals with equal worth in a way that is respectful of them as equal and valued individuals. Fundamental standards of care set out by the Care Quality Commission (CQC the health and care regulator) require service providers to take 'all reasonable steps' to ensure that individuals are treated with dignity and respect, including by upholding standards of privacy, autonomy and independence, and by ensuring that individual preferences are respected, and that individual needs are met (CQC, nd- $a$ ). The importance of support in meeting basic needs is also increasingly recognised as a critical corollary or a constituent element of dignity in health and care and conversely, denials or violations of dignity in care are increasingly recognised as occurring where support is needed but is not secured. For example, the official guidance accompanying the fundamental standard referred to above recognises that the provision of support in meeting individual needs may be necessary to maintain standards of dignity and respect. This guidance is particularly relevant where individuals experience activity of daily living (ADL) limitations and need support in relation to personal activities such as dressing, washing and eating. Provider responsibilities are further spelt out in a second fundamental standard focusing specifically on meeting individual nutritional and hydrational needs. This explicitly requires health and care service providers to take account of stated preferences and religious and cultural backgrounds, and to provide support with eating and drinking where this is needed (CQC, nd- $b$ ).

In this article, we assess older people's experiences of dignity and support with eating during hospital stays in England using a large nationally representative patient experience survey. The analysis builds on previous work we have undertaken in partnership with the British Equality and Human Rights Commission (EHRC), which has a statutory duty to monitor and report to Parliament on national equality and human rights outcomes. In early foundational work, Burchardt and Vizard (2011) recommended that in discharging this statutory duty, the EHRC should develop a national equality and human rights monitoring framework that is rooted theoretically in Amartya Sen's capability approach. The Equality Measurement Framework (EMF) was developed as a basis for this work and monitors the equality and human rights position of individuals and groups across ten domains of central and valuable capabilities. A national stakeholder consultation exercise was undertaken to identify and agree an indicator set for monitoring equality and human rights outcomes within and across each of the EMF domains, including policy experts and civil society intermediaries representing older people. The development of indicators that capture the extent to which hospital services maintain and support older people's dignity and respect, and that meet their needs for support with ADLs (including support needs related to nutritional wellbeing), was identified through the stakeholder consultation as an important priority. Indicators that capture these outcomes were subsequently developed and used by the EHRC as an input for its reporting to Parliament (e.g. EHRC, 2015). Initial methods and findings were set out in our earlier research report 
(Vizard and Burchardt, 2015) and the current article extends, deepens and updates this previous analysis.

There is a growing body of qualitative and quantitative evidence on older people's experiences of dignity, support with eating and nutritional wellbeing in the literature on ageing, health and nursing ageing. The issue of dignity in older age has moved up the research agenda and a growing literature addresses the issue of dignified care in community, primary, hospital and institutional contexts, and in specific areas such as palliative care and residential care institutions. Key studies address the relationship between dignity and ageing; examine older people's understandings and lived experiences of dignity; develop new operational survey measures of human dignity; address the constitutive elements of dignified care; and set out recommendations on policies and delivery (e.g. Woolhead et al., 2004; Gallagher et al., 2008; Tadd et al., 2011; Calnan et al., 2013; Black and Dobbs, 2014; Lloyd et al., 2014, 2017; Johnston et al., 2017; Coast et al., 2018; Tauber-Gilmore et al., 2018; Ota et al., 2019). Calnan et al. (2013) note that older age is one stage of the lifecourse where dignity is threatened due to the vulnerabilities created by increased incapacity, fragility and cognitive decline in combination with increasing dependency, lack of resources and other risk factors. Moreover, contact with health- and long-term care services - including acute hospital services - are contexts where dignity is most threatened because of patients' high levels of need and lack of control over their environment. The authors' in-depth study of dignity in the acute hospital context highlights the inconsistency of standards of dignity across hospitals, wards and even within wards at different times of day - with no ward found to be either totally 'dignified' or totally 'undignified'. Key elements of dignified care were found to include respectful communication, privacy, autonomy and a sense of control; meeting basic human needs such as nutrition, addressing personal hygiene needs in a respectful and sensitive manner; and empowerment, participation and information in relation to critical decisions. Conversely, undignified care was found to include care that renders individuals invisible, that depersonalises or objectifies them, or that is abusive, humiliating or disempowering (Tadd et al., 2011; Calnan et al., 2013).

A distinct body of literature addresses the critical importance of nutritional wellbeing in older age for longevity, good health and quality of life. Malnutrition is a key risk in older age and a growing body of research addresses this phenomenon in the hospital, long-term care and community contexts. Evidence from nutritional screening surveys conducted between 2007 and 2011 suggested that 25-34 per cent of patients admitted to hospital and 30-42 per cent of patients admitted to care homes were at risk of malnutrition, with the risks being higher among females than males and for older people aged 65 and over (British Association of Parenteral and Enteral Nutrition (BAPEN ), 2018a). In the hospital context, malnutrition has been found to be associated with increased length of stay, worse health outcomes, new institutionalisation and higher in-hospital mortality (NHS England, 2015; O'Shea et al., 2017), with identified risk factors for older adults including dementia, frailty, medical co-morbidities and ADL limitations (O'Shea et al., 2017). Recommended policy responses within the hospital services context include screening and nutritional assessment; the delivery of planned interventions to restore, maintain and support good nutrition and hydration; targeted 
interventions to meet the needs of high-risk groups including older people who experience complex problems, cognitive impairments and dementia; and the provision of support with eating where it is needed (NHS England, 2015; O'Shea et al., 2017; BAPEN, 2018b, nd; Murphy, 2019; Roberts et al., 2019). ${ }^{1}$

The current article builds on these bodies of literature. In addition, we contribute to a small but growing body of research that aims to develop and apply the capability approach developed by Amartya Sen and others as a framework for research on ageing and society. Our own proposals (Burchardt and Vizard, 2011) and related work being undertaken as part of the WHO healthy ageing agenda (WHO, $2015 a$ ) are discussed below. Other key references include several contributions that apply the capability approach as a basis for research on ageing (e.g. Grewal et al., 2006; Coast et al., 2008, 2018; Zaidi, 2011; Coast, 2014; Breheny et al., 2016; Venkatapuram et al., 2017; Gopinath, 2018; Stephens and Breheny, 2019) and a growing body of outputs that apply the capability approach as a research framework for examining health, disability and care (e.g. Burchardt, 2004; Prah Ruger, 2010; Burchardt and Vizard, 2011, 2014; Entwistle and Watt, 2013; Simon et al., 2013; Coast et al., 2015; Prah Ruger and Mitra, 2015; Mitchell et al., $2017 a, 2017 b$ ).

The article is organised as follows. The first section sets out our analytical framework. The second section examines the English policy context and the progress that has been made in embedding dignified care and support with meeting basic needs as specific goals that - like clinical outcomes - are explicitly addressed within policy and practice, and within broader systems for health and care regulation and inspection. In the third section, we highlight the role of national patient experience data in developing older-person-centred indicators and as a source of informational feedback and voice within processes of health-care improvement and reform. In the fourth section, we report our key empirical findings on older people's experiences of dignity and support with meeting basic needs such as eating during hospital stays in England using the Adult Inpatient Survey (AIS), including in-depth analysis for 2014 in the context of long-term and more recent trends, 2004-2019. Finally, the concluding section draws implications and lessons from the analysis and makes recommendations looking forward.

\section{Analytical framework}

Our analytical framework draws on our proposals for operationalising the capability approach as a basis for equality and human rights in the British context (Burchardt and Vizard, 2011). For international readers, the core ideas can be related to the WHO (2015a: 28) healthy ageing agenda which characterises healthy ageing as 'the process of developing and maintaining the functional ability that enables wellbeing in older age'. The analytical framework that underpins this definition was adopted by the WHO to achieve a paradigm shift away from a narrow model of healthy ageing focusing on the absence of disease and ADL limitations, towards a broader model of healthy ageing focusing on older people's wellbeing and quality of life. There are four key tenets of this analytical framework: a central focus on capabilities; modelling of the relationship between functional ability in older age and environmental and contextual factors; modelling of the role of health 
and long-term care services; and the adoption of a lifecourse perspective. These four key tenets are captured in Figure 1 and are examined in more detail below.

\section{Focus on capabilities}

First, the healthy ageing approach characterises older people's wellbeing and quality of life in terms of the capabilities that older people have to be and do the things that they have reasons to value (Figure 1, Box 1). The WHO highlights the need for a list of the valuable beings and doings through which to assess older people's wellbeing and emphasise the importance of older people's participation in developing and agreeing a list of this type, noting that some of the 'beings' and 'doings' that older people identify as important include role and identity; relationships; the possibility of enjoyment; autonomy (being independent and able to make own decisions); security; and the potential for personal growth. An indicative list of domains of functional ability is also proposed. This includes the abilities of older people to meet their own basic needs; to move around; to learn, grow and make decisions; to build and maintain relationships; and to contribute to society (e.g. WHO, 2015a: 26-34, 2020). Our own proposals have many elements in common with the WHO, and cover ten central and critical capabilities: life; health; living standards (including access to personal care); physical security; legal security; education and learning; productive and valued activities; individual, family and social life; identity, expression and self-respect; and participation, influence and voice. Dignity and autonomy are viewed as cross-cutting outcomes within and across these ten capabilities (Burchardt and Vizard, 2011). Other capability lists have been proposed, debated and used in the literature (for an overview, see Robeyns, 2017).

In the current article, we highlight how both dignity and nutritional wellbeing can be usefully characterised as being amongst the central and valuable capabilities that are critical for older people's wellbeing and quality of life. Being able to meet nutritional needs falls squarely within the first element of the WHO list and is fundamental to other capability lists that have been proposed in the literature, including our own. Whilst dignity is not explicitly mentioned in the WHO list, it is recognised in the underpinning World Report on Ageing and Health (WHO: $2015 a$ ), and the importance of dignity and self-respect is highlighted in the literature on the capability approach (e.g. Sen, 1983; Nussbaum, 2000; Zavaleta, 2007; Claassen, 2015), own proposals (Burchardt and Vizard, 2011). and the literature on dignity and ageing cited above.

\section{Modelling of the relationship between functional ability in older age and environmental and contextual factors}

Second, the healthy ageing approach characterises functional ability in older age as the 'health-related attributes that enable older people to be and to do the things that they have reasons to value' and models this as depending on intrinsic capacity (the personal physical and mental capacities of an individual), contextual or environmental factors (e.g. social norms and attitudes, the built environment, welfare and social security systems, and health and long-term care polices) and the 


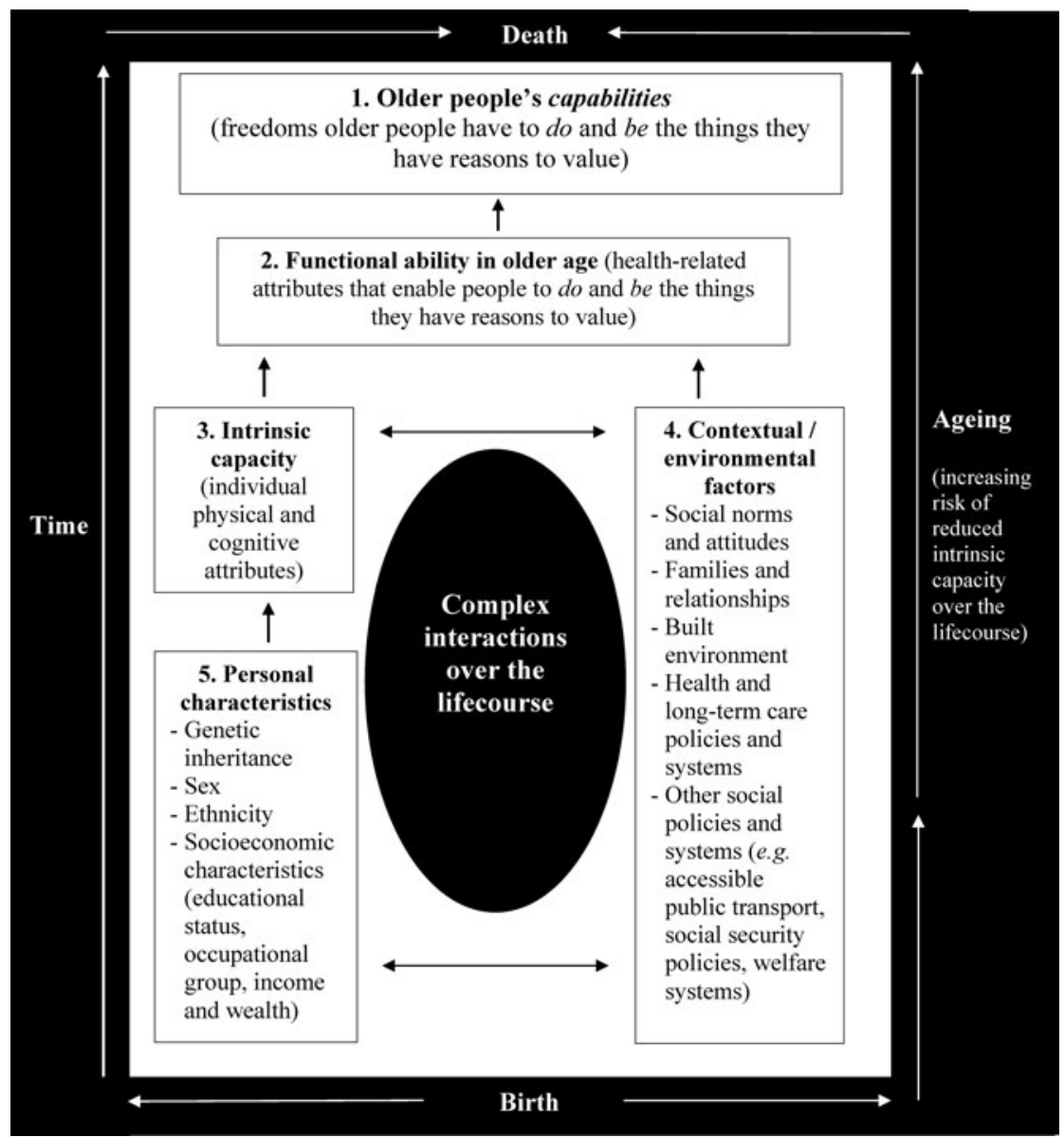

Figure 1. World Health Organization analytical model (healthy ageing over the lifecourse). Note: This figure is the authors' summary and representation of the WHO healthy ageing framework. WHO's explanation of the healthy ageing framework is set out in WHO (2015a).

interactions between these (Figure 1, Boxes 2-4). This modelling is important because it captures the ways in which environments and interventions that maintain and support functional ability can compensate for the increased risk of reduced intrinsic capacity in older age. The WHO cites the example of an older person who experiences physical capacity limitations but uses an assistive device and lives close to public transport that provides access for people with disabilities. Whereas this person enjoys the capability for mobility, another person who experiences the same physical limitation but who lives in a less-enabling environment does not (WHO, 2015a: 29).

The capabilities for dignity and nutritional wellbeing in older age can likewise be modelled in terms of interactions between intrinsic capacity and environmental and contextual factors. For example, support with eating can compensate for physical 
limitations that would otherwise reduce the capability for nutritional wellbeing in older age. Conversely, restrictions in the capability for dignity in older age can occur where physical and cognitive functioning is good, but environmental or contextual factors undermine older people's dignity or limit their sense of worth or self-respect.

\section{Modelling of the role of health and long-term care services}

Third, health and long-term care systems are identified in Figure 1 as one of the key environmental or contextual factors that can potentially influence capabilities, functional ability and wellbeing in older age, depending on their nature, scope and design (Box 4). The WHO notes that most current health systems are better designed to deal with individual acute health conditions than the more complex and chronic health needs that tend to arise with increasing age, and that existing health systems and care systems often operate independently leading to poorer outcomes, inefficient usage of services and cost shifting (WHO, nd). In contrast, the WHO has committed to the goal of transforming existing health and care systems in order to deliver services which are co-ordinated and integrated around older people's needs and that support healthy ageing as one of ten global priorities that the WHO aims to deliver by 2030 (WHO, 2015a, 2015b).

In terms of Figure 1, our working hypothesis is that the introduction of integrated and older-person-centred health-care systems will result in an expansion of functional ability, capabilities and wellbeing in older age. We conceptualise hospital services as one of the variables within broader health and long-term care environments that can potentially expand or constrain the capabilities for dignity and nutritional wellbeing in older age, depending on their nature, scope and design. Policy measures that improve older people's experiences of dignity during hospital stays, and that reduce unmet need for support with eating, are viewed as resulting in an expansion of older people's capability sets and their real opportunities and freedoms to do and be the things that they have reasons to value.

\section{Lifecourse perspective}

Fourth, the healthy ageing model illustrated in Figure 1 has a temporal dimension. Ageing is characterised as the process whereby the risk of reduced intrinsic capacity increases over the lifecourse (Figure 1, right-hand panel). Individual advantages and disadvantages are viewed as accumulating over a lifecourse and as resulting from complex interactions between personal characteristics (e.g. genetic inheritance, sex, ethnicity, income, wealth, education, occupation) and contextual or environmental factors (Figure 1, Boxes 3 and 5). Whilst lifecourse analysis is beyond the scope of the current article, we acknowledge the importance of longitudinal trajectories in explaining inequalities in the capabilities for dignity and nutritional wellbeing in older age. We also recognise that maximising the capabilities for dignity and nutritional wellbeing in older age requires public action, policies and interventions at many different stages of the lifecourse. 


\section{The English policy context}

In the English context, there is increasing recognition of older people's experiences of dignity and support with eating as key markers of high-quality and person-centred hospital services. Policy, political and media focus on this issue has been partly driven by a series of scandals in health-care provision for older people. From the mid-2000s onwards, a growing body of human rights and equality assessments, non-governmental organisation reports, evidence from health-care inspection, regulation and monitoring bodies, and findings from independent and public inquiries, raised concerns around older people's lack of treatment with dignity and respect, and lack of support with eating and drinking, within the English health and care systems. A report by a Parliamentary Committee on Human Rights (Joint Committee on Human Rights, 2007) raised concerns about older people's experiences of poor treatment, neglect, abuse, discrimination, lack of support for eating and drinking, and malnutrition and dehydration during hospital stays. Age UK subsequently highlighted lack of detection and treatment of malnutrition within hospital services as a 'national disgrace' and called on the Government to introduce compulsory monitoring of malnutrition (Age UK, 2010). The Patients Association (2011) examined 16 accounts of poor hospital care focusing on care communication, lack of access to pain relief, lack of assistance with toileting, and lack of help with eating and drinking. Lack of assistance with eating and drinking was also raised as a key concern in investigations by the Health Service Ombudsman (2011) into National Health Service (NHS) care of older people.

The health regulator (the CQC) responded to these growing concerns by undertaking two rounds of targeted inspection programmes on standards of dignity and nutrition within the NHS. It concluded that whilst in many instances standards were satisfactory, minimum standards of dignity and nutrition were not being complied with by some NHS bodies. There was evidence in some hospitals of older people not being given assistance to eat, not having their nutritional needs monitored and not being given enough to drink, and of staff not treating patients in a respectful way. In some cases, treatment was so poor that it was deemed to amount to a violation of legal rights (CQC, 2011, 2013a).

In 2013, the findings of the public inquiry into the care scandal at Mid Staffordshire NHS Foundation Trust (the Francis Inquiry) moved concerns about older people's experiences of dignity and support with ADLs, including assistance with eating, to the top of the policy, political and media agendas. Evidence of substandard care affecting older people was summarised in a press release:

The most basic standards of care were not observed, and fundamental rights to dignity were not respected. Elderly and vulnerable patients were left unwashed, unfed and without fluids. They were deprived of dignity and respect. Some patients had to relieve themselves in their beds when they [were] offered no help to get to the bathroom. Some were left in excrement stained sheets and beds. They had to endure filthy conditions in their wards. There were incidents of callous treatment by ward staff. Patients who could not eat or drink without help did not receive it. Medicines were prescribed but not given. The accident and emergency department as well as some wards had insufficient staff to deliver safe and effective care. Patients were discharged without proper regard for their welfare. (Mid Staffordshire NHS Foundation Trust Public Inquiry, 2013a) 
The Inquiry concluded that there had been a widespread failure of the health-care system, including regulatory as well as management failure, and put forward 290 wide-ranging recommendations with the aim of improving health-care services and broader systems of health-care monitoring, inspection and regulation in the future. This included recommendations on the introduction of new (legally binding) minimum standards of care; recommendations on the establishment of more effective systems for enforcing compliance with these standards, including more effective systems for regulation and inspection; and recommendations on the need for increased transparency and accountability (Mid Staffordshire NHS Foundation Trust Public Inquiry, 2013b).

The Government accepted the majority of the recommendations of the Francis Inquiry (Department of Health, 2013a, 2013b, 2013c, 2013d, 2013e) and during the run up to and in the wake of the Frances Inquiry, there were a series of important policy developments that aimed to improve patient experiences of hospital care radically, including specific initiatives to promote dignity and person-centred care and to improve support with meeting individual basic needs. This included a 'Compassion in Practice' strategy and a White Paper on reforming care and support (HM Government, 2012); patient experience guidelines (National Institute for Health and Care Excellence (NICE), 2012); a new duty of candour; strengthening of the inspection system following the Keogh Review (Keogh, 2013); and recognition of the rights to be treated with dignity and respect, and to receive suitable and nutritious food and hydration to sustain good health and wellbeing, in the revised NHS Constitution (Department of Health and Social Care, 2015). The fundamental standards of care discussed above were introduced, establishing requirements that service users be treated with dignity and respect and that their nutritional and hydrational needs are met (including through the provision of support where appropriate). Recommendations on safe staffing in acute hospital wards were published (NICE, 2014) and the number of nurses showed an upward trend in the immediate period following the Francis Inquiry (Vizard and Burchardt, 2015). Guidelines were published on the promotion of nutrition and hydration through commissioning (NHS England, 2015), and good practice was identified in relation to food standards and delivery (including 'protected mealtimes' without interruptions); malnutrition screening and assessments; support and assistance where physical functioning is restricted; and targeted interventions to meet the needs of older people who experience complex problems, cognitive impairments and dementia (BAPEN, 2018b, nd; Murphy, 2019; Malnutrition Taskforce, nd).

The importance of delivering integrated and person-centred health and care services also received increased attention in the period following the Francis Inquiry, driven by the NHS Five Year Forward View (NHS, 2014) and Long-term Plan (NHS England, 2019). The latter committed to the creation of locally based Integrated Care Systems which bring together acute, primary, community and social care services in order to provide joined-up services that are responsive to and meet individual needs. Within the acute hospital context, there is a growing emphasis on integrated wards models bringing together these services. There is increased recognition that failures of responsiveness and meeting older people's needs are more likely to occur when needs for support are not recognised, e.g. in the context of dementia patients. Holistic care assessments that recognise and address individual 
needs, including individual needs for support and assistance with ADLs including eating, and that plan for meeting these needs throughout the care pathway, are now recognised as building blocks of good practice (CQC, 2017: 19-32).

Nevertheless, a recent evaluation of how local organisations work together to meet the needs of older people in different local areas in England highlighted uneven developments across the country. Whilst there were instances of good practice, cases of poor practice and ineffective co-ordination of health and care services were also identified. Austerity-driven funding pressures were identified as one of the factors that have negatively impacted on progress to date and these pose ongoing challenges to the quality of care in the acute hospital sector (CQC, 2018, 2019: 6-8, 21-32, 50-55; cf. Vizard et al., forthcoming).

\section{Using patient experience surveys to develop person-centred health-care indicators for older people}

A further development in England in the period since the Frances Inquiry has been the increasing use of patient experience surveys for health policy, regulation and inspection purposes. The Inquiry highlighted the need for better use of a wider range of data within health-care policy and systems for monitoring, inspection and regulation, including more effective use of data on outcomes, complaints, incidents and investigations; implementation of systems for routine and risk-related monitoring; and the need both to hear, and to listen to, 'patient voice' and to make better use of the available patient experience data (Mid Staffordshire NHS Foundation Trust Public Inquiry, 2013b). The English patient survey programme now covers the acute and specialist hospital sector, mental health services, general practitioner services and social care. Information from these surveys has been increasingly used by the CQC for annual monitoring exercises, as a basis for provider-level performance tables and reports, and within the comprehensive inspection model / methdology introduced in 2014. Patient experience data have also been used by the Department of Health to evaluate progress against objectives specified in the NHS mandate and to hold NHS England to account for the outcomes achieved and for regulatory oversight of NHS trusts (CQC, 2013b, 2013c, 2013d, 2013e, 2013f, 2013g, 2014).

Increasing emphasis on patient experience data as a source of informational feedback and as a driver of person-centred health care is also reflected in other countries and contexts. The growing number of national and international surveys used to measure patient experience are reviewed in Garratt et al. (2008), Fujisawa and Klazinga (2017) and Larson et al. (2019), and a new set of internationally comparable patient experience indicators were included in the recent Health at a Glance report (Organisation for Economic Co-operation and Development (OECD), $2019 a) .{ }^{2}$ The latter notes that the patient perspective on the outcomes and experience of their care is essential in driving continuous quality improvement of health services and in increasing the responsiveness of health policy and health systems to different people's needs. Patient experience data also have the potential to address knowledge gaps on neglected health-care quality outcomes, ranging from experiences of dignity and respect during childbirth in East Africa (Larson et al., 2019), to experiences of care for individuals with chronic conditions within community and ambulatory settings (OECD, 2019b). 
The increasing availability of patient experience data both in England and internationally provides an important new data source for research on older people's health-care outcomes. Indeed, it is critical that these survey instruments are fully exploited for the purposes of research on older people and as means of giving voice to older people's experiences, concerns and interests within processes of health-care improvement and reform. Our work with the EHRC highlighted the feasibility of developing new indicators of older people's experiences in health care drawing on national patient experience data and resulted in the publication of an initial round of data on older people's experiences of dignity and support with eating during hospital stays (e.g. EHRC, 2015). Our previous research report (Vizard and Burchardt, 2015) made further progress by undertaking more detailed analysis of the 2012 AIS and by addressing some of the methodological challenges involved in using subjective, self-reported data to monitor older people's health-care experiences.

Two of the recommendations in Vizard and Burchardt (2015) have particular resonance for the methods adopted in the research exercise below. First, we recommend that caution needs to be exercised in making strict comparisons between older and young people's responses to patient experience surveys. This is because of the phenomena of adaptive expectations (whereby older people may lower their expectations as they adapt to their situation over time) and/or age-related expectations (whereby different age cohorts have systematically different expectations). Vizard and Burchardt (2015) and several previous studies (Healthcare Commission, 2005; Ipsos MORI, 2008; Sizmur, 2011) identify a positive association between reported inpatient experiences and age, with older people reporting better experiences than their younger counterparts. However, this finding is difficult to reconcile with the body of qualitative, case study, inspection and public inquiry evidence cited above. As the Healthcare Commission (2006: 17-18) notes, one possible explanation for this observed response pattern is that the expectations of older people might be systematically lower than those of other age groups and that 'gratitude bias' (where individuals understate the shortcomings of health services because they are grateful or relieved to be free of a particular illness, or believe that medical professionals are beyond criticism) plays an important role (cf. Bleich et al., 2009; Sizmur, 2011). ${ }^{3}$

Second, Vizard and Burchardt (2015) cautioned against examining and reporting on the experiences of those aged over 65 as a single group. The population over 65 is heterogeneous and it is critical to examine inequalities of patient experience within the older population and to identify and report separately on the position of the frail and disabled older population and those with long-standing conditions. For these reasons, we recommend undertaking narrow-band age disaggregation within the older population, with separate identification of the experiences of the 'oldest of the old' (those aged 80 or above). In addition, we analyse inequalities in risks and vulnerabilities within the older population by considering the interactions between older age, disability and gender.

\section{Empirical findings using the 2014 AIS}

We report nationally representative prevalence and headcount estimates of older people's experiences of dignity and respect, and support with eating, during 
hospital stays using the 2014 AIS. In addition, we present multivariate analysis of the predictors of unmet need for support with eating during hospital stays using logistic regression techniques. This outcome was selected for further analysis because of the importance of good nutrition for health outcomes, and because it is a critical component of dignified treatment.

\section{Dataset}

The AIS is a repeated cross-sectional study covering acute and specialist trusts and has been conducted annually since 2002. The sampling targets a flow of 850 consecutively discharged inpatients within a given time window (usually June to August) and uses postal questionnaires. Individuals are eligible if they are over 16 years of age and had at least one overnight stay in hospital. Exclusions include maternity, terminations, psychiatric, day cases and private patients.

The 2014 AIS covered 154 trusts and 59,083 inpatients with a response rate of 47 per cent. We focus on 2014 because a secure and tailored version of the dataset was provided as a basis for the analysis based on an agreement with the CQC. This includes the detailed fine-grained information on age and data on limiting longterm illness and disability that we need for the study. Trust-level deprivation data published by the Health and Social Care Information Centre (2016) has been matched into the dataset using three-digit hospital trust identifiers. This captures the proportion of finished spells of care where the patient lives within the most deprived quintile (based on the Index of Multiple Deprivation). This information is used to rank hospitals from least to most deprived, and this distribution is divided into tenths, to generate our 'hospital deprivation' variable.

To set the 2014 data in context, we also report overall trends for the period 2004-2019 using standard AIS datasets available at the UK Data Archive and published CQC data, without fine-grained sub-group information.

\section{Methods}

The AIS asks about a range of experiences relating to waiting times, admissions and quality of care during their hospital stay. We focus on responses to two questions. The first question asks: 'Overall, did you feel you were treated with respect and dignity while you were in the hospital?' Response options include 'yes, always', 'yes, sometimes' and 'no'. The second question asks: 'Did you get enough help from staff to eat your meals?' Response options include 'yes, always', 'yes, sometimes', 'no' and 'I do not need help to eat meals'. For both questions, we interpret positive responses ('yes, always') as evidence of a satisfactory standard of care; negative responses ('no') as evidence of a poor standard of care; and intermediate responses ('yes, sometimes') as evidence of an inconsistent standard of care. In the analysis of help with eating, the proportion of inpatients who need help with eating is estimated based on the selection of response options 'yes, always', 'yes, sometimes' or 'no' as opposed to response option 'I do not need help to eat meals'.

We first report national prevalence and headcount estimates for 2014. These estimates use new patient-level weights which aim to make our estimates more representative of the adult inpatient population by adjusting for the effects of 
differential non-response between sub-groups (age, sex and emergency/elective route of admission) and the size of each trust's inpatient population. These have been developed because at the time the analysis was undertaken the standard weights used to analyse AIS give each trust equal weight in the overall results and are not ideal for individual-level patient-focused analysis because hospitals vary in size. ${ }^{4}$ In addition, to contextualise the findings, we examine trends over the period 2004-2019.

For the multivariate analysis, multilevel logistic regression analysis has been undertaken to examine the independent associations between unmet need for support with eating and a range of explanatory factors. The model we develop focuses on the capability to meet individual nutritional needs, with the dependent variable coded 0 if an individual does not need help with eating, or needs help and received it, and coded 1 if the person needs support and did not receive it. Four groups of independent variables are introduced sequentially into the model. These focus on inpatient characteristics, hospital-level deprivation, inpatient pathways and broader dimensions of quality of care. The sequential ordering reflects the extent to which these factors are, or are not, within the control of an individual hospital. The multilevel specification is justified by the hierarchical nature of the underlying model, with patients clustered or 'nested' in hospital trusts (on which, see Sizmur, 2011; Sizmur and Korner, 2013). The main multivariate results are reported in Table 2, Model 4 (this is the full multilevel model covering all respondents). Results based on alternative model specifications are reported where they are of substantive interest.

We argue that both unadjusted and adjusted estimates of patient experience are informative. Unadjusted estimates indicate the magnitude of the problem overall and which hospitals face the biggest challenge. Adjusted estimates take account of patient mix and other hospital-level factors, and suggest which trusts are doing a better or worse job given the nature of the population they serve and their resourcing. However, since some of the variables included in the later models reflect factors that are, at least to some extent, under the control of the hospital (such as staffing levels and patient pathways), we are careful to show estimates both before and after taking these into account.

\section{Dignity and respect}

The results in Table 1 show that poor or inconsistent standards of dignity and respect affected 22 per cent of adult inpatients in England in 2014, including 4 per cent who reported poor standards. Experiences of poor and inconsistent standards of treatment are observed to be higher for women compared to men, and for individuals who experience a long-standing limiting illness or disability, compared with those who do not. The percentage of inpatients who report that they experienced 'not' being treated with dignity and respect is observed to decline with age, with a small upturn for the oldest age group. However, we caution against comparisons across broad age bands.

Looking at the variations within the older population (aged above 65 years), experiences of poor or inconsistent standards are higher for individuals aged over 80, for those who experience a long-standing limiting illness or disability, and for women. Examining prevalence by the intersection of these characteristics, 
Table 1. Inpatient experiences of dignity and help with eating (2014, weighted)

\begin{tabular}{|c|c|c|c|c|c|c|c|c|}
\hline & \multicolumn{4}{|c|}{ Dignity and respect } & \multicolumn{4}{|c|}{ Help with eating } \\
\hline & $\begin{array}{l}\text { Prevalence } \\
\text { (\% of all } \\
\text { respondents) }\end{array}$ & $\begin{array}{c}\text { Number } \\
\text { affected } \\
\text { per } \\
\text { annum }\end{array}$ & $\begin{array}{l}\text { Prevalence } \\
\text { (\% of all } \\
\text { respondents) }\end{array}$ & $\begin{array}{l}\text { Number } \\
\text { affected } \\
\text { per } \\
\text { annum }\end{array}$ & $\begin{array}{c}\text { Prevalence } \\
\text { (\% of those } \\
\text { who need } \\
\text { help) }\end{array}$ & $\begin{array}{c}\text { Number } \\
\text { affected } \\
\text { per } \\
\text { annum }\end{array}$ & $\begin{array}{c}\text { Prevalence } \\
\text { (\% of those } \\
\text { who need } \\
\text { help) }\end{array}$ & $\begin{array}{c}\text { Number } \\
\text { affected } \\
\text { per } \\
\text { annum }\end{array}$ \\
\hline \multicolumn{9}{|l|}{ Age: } \\
\hline 16-35 (Ref.) & 7.8 & 111,721 & 36.2 & 516,637 & 21.3 & 99,624 & 42.8 & 200,395 \\
\hline $36-50$ & $5.8^{\star}$ & 141,173 & $28.2^{*}$ & 682,990 & $19.5^{\star}$ & 149,164 & $38.9^{*}$ & 298,018 \\
\hline $51-65$ & $3.5^{\star}$ & 92,783 & $20.6^{\star}$ & 541,195 & $17.0^{\star}$ & 123,011 & $33.1^{*}$ & 239,411 \\
\hline Male (Ref.) & 3.0 & 176,815 & 17.6 & $1,052,313$ & 15.7 & 294,943 & 35.0 & 839,500 \\
\hline Female & $4.3^{*}$ & 294,719 & $25.2^{\star}$ & $1,708,732$ & $21.1^{*}$ & 406,288 & $43.6^{*}$ & 658,726 \\
\hline \multicolumn{9}{|l|}{ Disability: } \\
\hline $\begin{array}{l}\text { No LLID } \\
\text { (Ref.) }\end{array}$ & 2.8 & 169,963 & 18.2 & $1,116,567$ & 15.7 & 228,188 & 32.1 & 466,438 \\
\hline LLID & $5.0^{*}$ & 251,047 & $26.8^{\star}$ & $1,351,814$ & $21.3^{*}$ & 387,930 & $46.3^{*}$ & 843,545 \\
\hline
\end{tabular}




\begin{tabular}{|c|c|c|c|c|c|c|c|c|}
\hline \multicolumn{9}{|l|}{ Interactions: } \\
\hline $\begin{array}{c}\text { Aged }>80 \\
\text { with disability }\end{array}$ & 3.4 & 41,453 & 23.9 & 305,573 & 23.6 & 128,980 & 57.1 & 312,550 \\
\hline $\begin{array}{l}\text { Aged }>80 \text {, } \\
\text { with disability, } \\
\text { and female }\end{array}$ & 3.6 & 27,279 & 25.9 & 198,282 & 25.2 & 84,552 & 61.2 & 205,542 \\
\hline
\end{tabular}

Notes: A tailored version of the 2014 dataset was used for the analysis based on an agreement with the Care Quality Commission (CQC). The data are weighted using a new set of patient-level weights. These have been calculated using a differential non-response variable provided by the COC and a grossing-variable that takes account of the size of local inpatient populations which has been derived from Hospital Episode Statistics data (Health and Social Care Information Centre, 2015a, 2015b). Specialist trusts have been grouped for this analysis. The disability variable

has been derived from responses to Question 74 (on long-standing conditions) and Question 75 (on difficulties). Missings have been dropped from the calculations in this table and estimates have been rounded to one decimal point. Rows may not sum exactly to 100 per cent and sub-totals may not sum to 'All'. Ref.: reference group. LLID: longstanding limiting illness or disability.

Source: Authors' calculations using the Adult Inpatient Survey, 2014.

Significance level: Significance testing has been undertaken at the 95 per cent level using a one-variable logistic regression test. * Significance difference between the percentage reported by a sub-group and the reference group. 
Table 2. Estimates of the factors associated with a high probability of receiving poor or inconsistent help with eating (odds ratios from multilevel models, Models 1-5)

\begin{tabular}{|c|c|c|c|c|c|c|}
\hline & Null model & $\begin{array}{c}\text { Model } 1 \\
\text { (inpatient } \\
\text { characteristics) }\end{array}$ & $\begin{array}{c}\text { Model } 2 \\
\text { (+ hospital-level } \\
\text { deprivation) }\end{array}$ & $\begin{array}{c}\text { Model } 3 \\
\text { (+ inpatient } \\
\text { pathway) }\end{array}$ & $\begin{array}{l}\text { Model } 4 \text { (full } \\
\text { model, all } \\
\text { respondents) }\end{array}$ & $\begin{array}{l}\text { Model } 5 \text { (restricted } \\
\text { sample: } \\
\text { respondents who } \\
\text { need help with } \\
\text { eating) }\end{array}$ \\
\hline \multicolumn{7}{|l|}{$\begin{array}{l}\text { Group 1: Inpatient } \\
\text { characteristics: }\end{array}$} \\
\hline \multicolumn{7}{|l|}{ Sex: } \\
\hline Male & & 1 & 1 & 1 & 1 & 1 \\
\hline Female & & $1.277^{\star \star \star}$ & $1.271^{\star \star \star}$ & $1.294^{\star * *}$ & $1.137^{\star}$ & $1.290^{\star \star \star}$ \\
\hline \multicolumn{7}{|l|}{ Disability: } \\
\hline No LLID & & 1 & 1 & 1 & 1 & 1 \\
\hline LLID & & $1.786^{\star \star \star}$ & $1.772^{\star \star \star}$ & $1.739^{\star \star \star}$ & $1.363^{\star \star \star}$ & 1.025 \\
\hline \multicolumn{7}{|l|}{ Age group: } \\
\hline $16-35$ & & 1 & 1 & 1 & 1 & 1 \\
\hline $36-50$ & & $0.815^{\star}$ & 0.916 & 0.897 & 0.924 & 0.853 \\
\hline $51-65$ & & $0.619^{\star \star \star}$ & $0.650^{\star \star \star}$ & $0.638^{\star \star \star}$ & $0.760^{\star}$ & 0.874 \\
\hline $66-80$ & & $0.446^{\star \star \star}$ & $0.470^{\star \star \star}$ & $0.462^{\star \star \star}$ & $0.648^{\star \star \star}$ & $0.771^{\star}$ \\
\hline$>80$ & & $0.559^{\star \star \star}$ & $0.593^{\star \star \star}$ & $0.574^{\star \star \star}$ & 0.822 & 0.806 \\
\hline \multicolumn{7}{|l|}{ Proxy: } \\
\hline No - patient & & 1 & 1 & 1 & 1 & 1 \\
\hline A friend or relative & & $4.363^{\star \star \star}$ & $4.427^{\star \star \star}$ & $4.351^{\star \star \star}$ & $3.981^{\star \star \star}$ & $1.973^{\star \star \star}$ \\
\hline $\begin{array}{l}\text { Both patient and } \\
\text { friend/relative }\end{array}$ & & $3.113^{\star \star \star}$ & $3.206^{\star \star \star}$ & $2.980^{\star \star \star}$ & $2.807^{\star \star \star}$ & $1.982^{\star \star \star}$ \\
\hline $\begin{array}{l}\text { Patient with the help } \\
\text { of another }\end{array}$ & & $2.414^{\star \star \star}$ & $2.320^{\star \star \star}$ & 1.807 & 1.676 & 0.811 \\
\hline
\end{tabular}


Group 2: Hospital-level

deprivation:

Hospital deprivation:

\begin{tabular}{|c|c|c|c|c|}
\hline 1 (least deprived) & 1 & 1 & 1 & 1 \\
\hline 2 & 0.972 & 0.962 & 0.989 & 1.005 \\
\hline 3 & 0.924 & 0.911 & 0.921 & 0.937 \\
\hline 4 & 0.932 & 0.907 & 0.772 & $0.752^{\star}$ \\
\hline 5 & 1.044 & 1.029 & 0.984 & 1.000 \\
\hline 6 & 1.173 & 1.109 & 1.015 & 0.993 \\
\hline 7 & 1.063 & 1.077 & 1.081 & 1.183 \\
\hline 8 & 1.090 & 1.057 & 0.979 & 0.898 \\
\hline 9 & 0.956 & 0.911 & 0.845 & 0.827 \\
\hline 10 (most deprived) & $1.315^{\star}$ & 1.240 & 1.167 & 1.032 \\
\hline
\end{tabular}

Group 3: Inpatient

pathway:

Had operation:

\begin{tabular}{|c|c|c|c|}
\hline No & 1 & 1 & 1 \\
\hline Yes & 1.033 & 0.968 & 0.961 \\
\hline \multicolumn{4}{|c|}{ Critical care area: } \\
\hline No & 0.985 & $0.872^{\star}$ & 1.127 \\
\hline
\end{tabular}


Table 2. (Continued.)

\begin{tabular}{|c|c|c|c|c|c|c|}
\hline & Null model & $\begin{array}{c}\text { Model } 1 \\
\text { (inpatient } \\
\text { characteristics) }\end{array}$ & $\begin{array}{c}\text { Model } 2 \\
\text { (+ hospital-level } \\
\text { deprivation) }\end{array}$ & $\begin{array}{c}\text { Model } 3 \\
\text { (+ inpatient } \\
\text { pathway) }\end{array}$ & $\begin{array}{l}\text { Model } 4 \text { (full } \\
\text { model, all } \\
\text { respondents) }\end{array}$ & $\begin{array}{l}\text { Model } 5 \text { (restricted } \\
\text { sample: } \\
\text { respondents who } \\
\text { need help with } \\
\text { eating) }\end{array}$ \\
\hline \multicolumn{7}{|l|}{ Admission route: } \\
\hline Emergency/urgent & & & & 1 & 1 & 1 \\
\hline $\begin{array}{l}\text { Waiting list/planned in } \\
\text { advance }\end{array}$ & & & & 0.996 & $1.205^{\star \star}$ & 1.140 \\
\hline Other & & & & 1.036 & 1.057 & 1.026 \\
\hline \multicolumn{7}{|l|}{ Length of stay: } \\
\hline 1 day & & & & 0.987 & $0.849^{\star}$ & 0.892 \\
\hline$>1$ day, <1 week & & & & 1 & 1 & 1 \\
\hline $\begin{array}{l}\text { More than } 1 \text { week, up } \\
\text { to } 2 \text { weeks }\end{array}$ & & & & 1.074 & 1.153 & 0.980 \\
\hline $\begin{array}{l}\text { More than } 2 \text { weeks, up } \\
\text { to a month }\end{array}$ & & & & $1.476^{\star \star \star}$ & $1.462^{\star \star \star}$ & 1.098 \\
\hline More than a month & & & & $1.515^{\star \star}$ & 1.295 & 0.787 \\
\hline \multicolumn{7}{|l|}{ Number of wards: } \\
\hline 1 & & & & 1 & 1 & 1 \\
\hline 2 & & & & $1.194^{\star \star}$ & 1.047 & 0.993 \\
\hline 3 or more & & & & $1.617^{\star \star \star}$ & 1.187 & 0.995 \\
\hline \multicolumn{7}{|l|}{$\begin{array}{l}\text { Group 4: Nursing and } \\
\text { food services: }\end{array}$} \\
\hline Nurses: & & & & & & \\
\hline
\end{tabular}




\begin{tabular}{|c|c|c|c|c|c|c|}
\hline $\begin{array}{l}\text { Always/nearly always } \\
\text { enough }\end{array}$ & & & & & 1 & 1 \\
\hline Sometimes enough & & & & & $2.017^{\star \star *}$ & $1.968^{\star \star \star}$ \\
\hline $\begin{array}{l}\text { Rarely or never } \\
\text { enough }\end{array}$ & & & & & $3.942^{\star \star \star}$ & $4.341^{\star \star \star}$ \\
\hline \multicolumn{7}{|l|}{ Quality of nurses: } \\
\hline Not poor & & & & & 1 & 1 \\
\hline Poor & & & & & $3.418^{\star \star \star}$ & $3.508^{\star \star \star}$ \\
\hline \multicolumn{7}{|l|}{ Choice of food: } \\
\hline Yes, always & & & & & 1 & 1 \\
\hline Yes, sometimes & & & & & $2.207^{\star \star \star}$ & $2.125^{\star \star \star}$ \\
\hline No & & & & & $3.582^{\star \star \star}$ & $6.734^{\star \star \star}$ \\
\hline Number of observations & 57,057 & 49,415 & 42,718 & 37,662 & 37,230 & 10,067 \\
\hline \multicolumn{7}{|l|}{ Model information: } \\
\hline Number of groups & 141 & 141 & 135 & 135 & 135 & 135 \\
\hline $\begin{array}{l}\text { Observations per } \\
\text { group }\end{array}$ & $219-6,073$ & $193-5,371$ & $193-445$ & $160-380$ & $156-373$ & $50-104$ \\
\hline Constant & 0.052 & 0.041 & 0.037 & 0.032 & 0.014 & 0.058 \\
\hline Variance of constant & 0.065 & 0.061 & 0.046 & 0.043 & 0.019 & 0.013 \\
\hline $\begin{array}{l}\text { Intraclass correlation } \\
\text { coefficient }\end{array}$ & 0.020 & 0.018 & 0.014 & 0.013 & 0.006 & 0.004 \\
\hline $\begin{array}{l}\text { Covariance matrix } \\
\text { (encode2) }\end{array}$ & 0.065 & 0.061 & 0.046 & 0.061 & 0.019 & 0.013 \\
\hline Log likelihood & $-11,039.8$ & $-8,871.5$ & $-7,856.8$ & $-6,672.6$ & $-5,783.6$ & $-3,784.7$ \\
\hline
\end{tabular}

Notes: A tailored version of the 2014 dataset was used for the analysis based on an agreement with the Care Quality Commission. LLID: longstanding limiting illness or disability. Source: Authors' calculations using the Adult Inpatient Survey, 2014.

Significance levels: ${ }^{\star} p<0.05,{ }^{* *} p<0.01,{ }^{* * *} p<0.001$. 


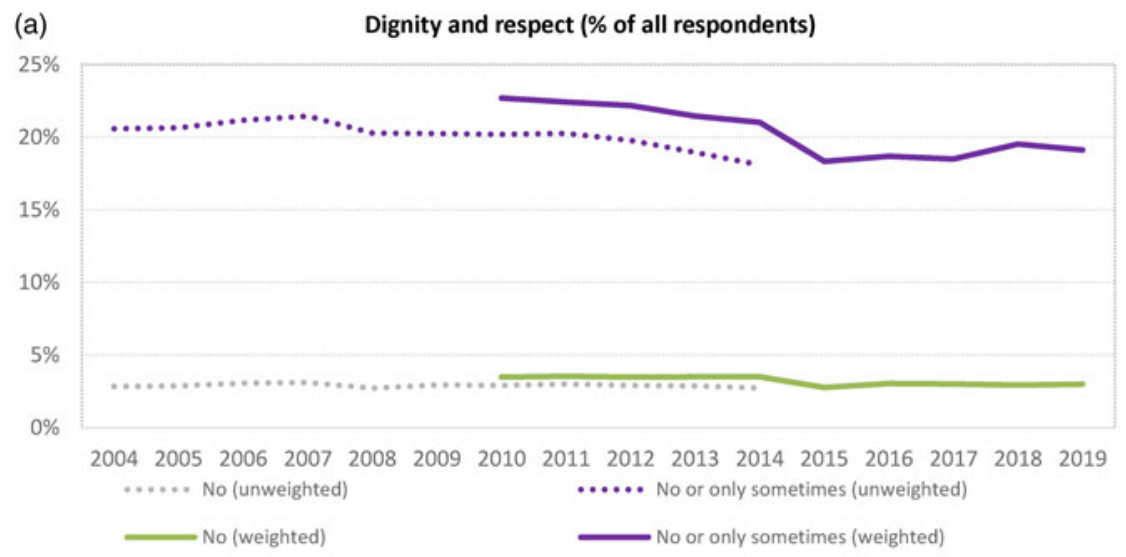

(b)

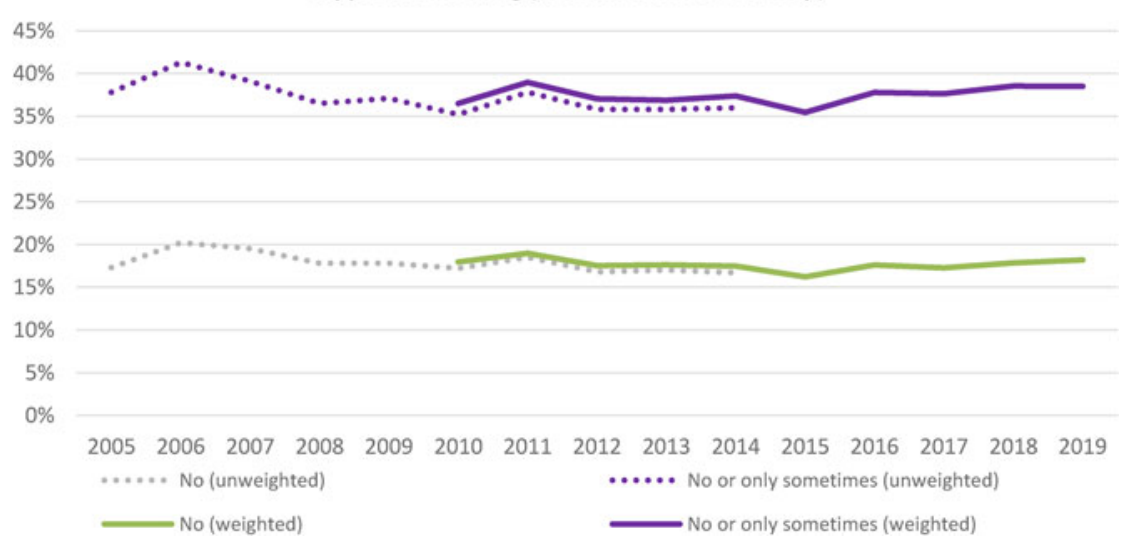

Figure 2. Trends in the percentage of patients reporting not being treated with dignity and respect or not receiving help with eating, 2004-2019.

Sources: Estimates for 2004-2014 (dotted lines) are the authors' own calculations using Adult Inpatient Survey microdata (annual versions deposited at the UK Data Archive) and are unweighted. Estimates for 2010-2019 (solid line) are weighted estimates published in Care Quality Commission (2020).

poor or inconsistent standards of dignity and respect affected approximately 26 per cent of women over 80 who experienced a long-standing limiting illness or disability.

The headcount estimates suggest that almost 2.8 million inpatients were affected by poor or inconsistent standards of dignity and respect on an annual basis, of whom about one million were aged over 65 . We estimate that around 306,000 people aged over 80 who experienced a long-standing limiting illness or disability were affected by poor or inconsistent standards of dignity and respect in 2014, around 190,000 of whom were female.

Figure $2 \mathrm{a}$ shows that there was remarkably little change in overall prevalence of poor or inconsistent experiences of dignity and respect between 2004 and 2019. A shallow decline in prevalence of poor or inconsistent standards is however apparent 
in both the unweighted and weighted data series, particularly in the period after 2010 with a notable improvement in 2015 , when prevalence rates were at a minimum. An optimistic interpretation of these results would point out that this period of improvement coincides with increased policy focus in the run up to and wake of the Frances Inquiry. The deterioration in more recent data points could be associated with the austerity-driven workforce and resource constraints examined in Vizard et al. (forthcoming), but this remains speculative.

\section{Support with eating}

We estimate that in 2014, around one-third of survey respondents (30\%) reported needing support with eating during their hospital stay. This is a substantial proportion points towards support with eating being relevant for large numbers of inpatients - around 3.8 million people a year on an annual basis - rather than being a marginal or specialist issue. The prevalence estimates show that poor or inconsistent standards affected 39 per cent of inpatients who needed help during their hospital stay in England in 2014, including 18 per cent experiencing poor standards (Table 1).

Risks of experiencing poor or inconsistent standards are observed to have a negative association with age, although again we caution against comparisons across broad age bands. Looking at variations within the population aged over 65, reported experiences of poor or inconsistent standards of care support are higher for individuals aged over 80, for women, and for those who experience a long-standing limiting illness or disability. Again, these risks compound, with poor or inconsistent standards affecting 61 per cent of women over 80 who experienced a long-standing limiting illness or disability - a staggering figure, and a clear majority.

The headcount estimates suggest that around 1.5 million inpatients were affected by poor or inconsistent standards in 2014, of whom about 760,400 were aged 65 or over. Around two-thirds of those who needed help but did not get adequate help reported that they experience a limiting long-standing illness or disability. We estimate that 313,000 people over 80 who experience disabilities were affected by poor or inconsistent standards in 2014, of whom 206,000 were female.

Figure $2 \mathrm{~b}$ shows that there was remarkably little change in reported experiences of support with eating between 2005 and 2019. An increase in 2011 was followed by a shallow downward trend which accelerated in 2015, when the prevalence of poor or inconsistent experiences was again at a minimum, again perhaps reflecting policy focus and some success in relation to strategies to promote nutritional wellbeing in the wake of the Frances Inquiry. An upward trend is again observed after 2015 which, as in the context of dignity and respect, may reflect the impact of rising workforce and resource constraints during a period of low annual increases in public expenditure on health care (on which, see Vizard et al., forthcoming).

\section{Hospital-level variation}

Figure 3 shows the percentages of inpatients who reported poor or inconsistent standards of dignity and respect (Figure 3a) and support with eating (Figure 3b) within each hospital trust in 2014. These are raw percentages, not adjusted for patient mix. 
(a)

Dignity and respect (\% of all respondents)

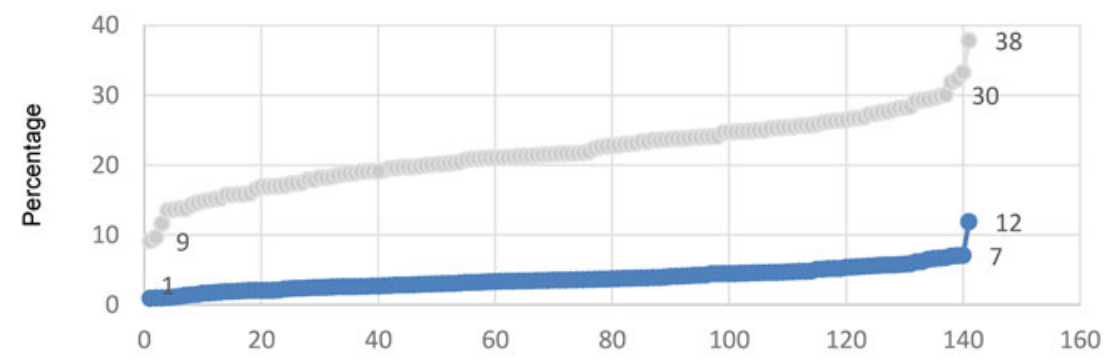

(b)

Help with eating (\% of those who need help)

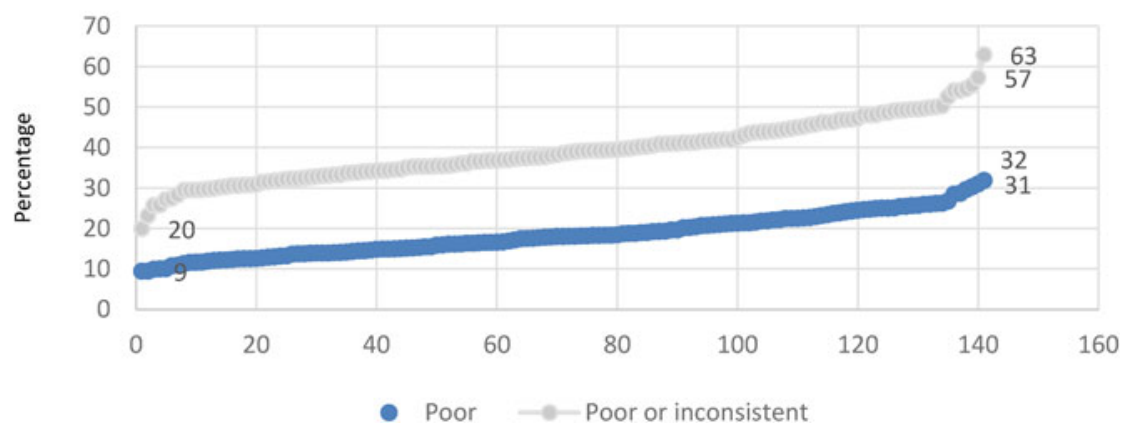

Figure 3. Inpatient experiences of dignity and help with eating by hospital trust (2014, weighted). Notes: A tailored version of the 2014 dataset was used for the analysis based on an agreement with the Care Quality Commission (CQC). The data are weighted using a new set of patient-level weights. These have been calculated using a differential non-response variable provided by the CQC and a grossing-variable that takes account of the size of local inpatient populations which has been derived from Hospital Episode Statistics data (Health and Social Care Information Centre, 2015a, 2015b). Each dot represents a hospital trust, with the exception of specialist trusts which have been grouped for this analysis. They are ordered left to right from 'best' to 'worst'.

Source: Authors' calculations using the Adult Inpatient Survey, 2014.

Several trusts are observed to have particularly high percentages reporting poor and inconsistent standards. Likewise, several trusts (including the group of specialist trusts, which are here represented as a single observation) are observed to have considerably lower percentages. The percentage reporting poor standards of dignity and respect varied from 1 per cent within trusts at the 'better' end of the spectrum to 12 per cent amongst worst performers, with an average of 3.7 per cent. The percentage reporting poor or inconsistent standards varied from 9 to 38 per cent, with an average of 22 per cent. Amongst those who reported needing help with eating within each trust, the percentage reporting poor standards varied from 9 per cent within trusts at the 'better' end of the spectrum to 32 per cent amongst worst performers, with an average of 18 per cent. The proportion reporting poor or inconsistent standards varied from 20 to 63 per cent, with an average of 39 per cent. 


\section{Predictors of unmet need for support with eating}

The multivariate results show that being female rather than male, and experiencing a disability compared to not experiencing a disability, have positive associations with unmet need for support with eating after controlling for other factors (Table 2, Model 4). An extended version of the model includes an interaction term between age and disability. These results show that the effects of age are moderated by disability, with point estimates suggesting that disability increases the probability of experiences of poor care within each age group over 35, and significantly so for the 51-65 age group and especially for people over 80 (Table 3, Model 6).

The findings above are reported after controlling for proxy responses to the survey - where the form was filled by a friend, the patient and a friend together, or by a health professional. However, proxy responses arguably provide an important source of information in their own right (rather than simply being viewed as a source of noise or error). Separate analysis, not shown in the table, indicates that proxy responses are more prevalent amongst people over 80 than in other bands (with only 66\% filling in their forms 'by themselves') and are more negative than responses in general. This pattern is confirmed by the multivariate analysis, which shows a statistically significant association between proxy responses and lack of support with eating after controlling for other factors (Table 2, Model 4). There are at least two possible interpretations of this finding. One is that 'gratitude bias' is less prevalent among relatives, friends and professionals - they are more likely to state that help was not received when needed than the 'uncomplaining' patient themselves. Second, it is also possible that relatives, friends and professionals are more motivated to assist patients filling in their survey responses, or to fill them in on their behalf, where they feel the patient was poorly treated (a 'selection effect').

Turning to the relationship between unmet need for support with eating and hospital-level deprivation, unadjusted analysis suggests a positive association between poor standards of help with eating and higher hospital-level deprivation. This association remains statistically significant when the first set of independent variables (patient characteristics) is incorporated into the model. However, once patient pathway information is included (Table 2, Model 3 onwards), the association between unmet need for support with eating and hospital-level deprivation becomes statistically non-significant.

The group of independent variables introduced in Model 3 (Table 2) relate to patient pathway and broader dimensions of quality of care. Here, statistically significant associations are observed between unmet need for support with eating and being a non-emergency admission, and between unmet need for support with eating and staying in a critical care unit. Neither of these effects are statistically significant in the version of the model (Model 5) which restricts the sample by excluding patients with no need for assistance with eating. Staying in three or more wards, and having a longer length of stay (of between two and four weeks), are found to be important factors based on Model 3 (patient pathway model), although the effect of the former becomes statistically insignificant when all factors are controlled for (Model 4), and neither effect is statistically significant under the restricted specification (Model 5). 
Table 3. Estimates of the factors associated with a high probability of receiving poor or inconsistent help with eating (odds ratios from multilevel interaction models, Models 6 and 7)

\begin{tabular}{|c|c|c|}
\hline & $\begin{array}{l}\text { Model } 6 \text { (full } \\
\text { interaction model, all } \\
\text { respondents) }\end{array}$ & $\begin{array}{l}\text { Model } 7 \text { (full interaction model, } \\
\text { restricted sample: respondents who } \\
\text { need help with eating) }\end{array}$ \\
\hline No disability & 1 & 1 \\
\hline Disability & 0.969 & 1.000 \\
\hline \multicolumn{3}{|l|}{ Age group: } \\
\hline (1) $16-35$ & 1 & 1 \\
\hline (2) $36-50$ & 0.909 & 0.928 \\
\hline (3) $51-65$ & $0.629^{\star \star}$ & 0.836 \\
\hline (4) $66-80$ & $0.587^{\star \star \star}$ & 0.858 \\
\hline$(5)>80$ & $0.566^{\star \star \star}$ & $0.606^{\star \star}$ \\
\hline No disability - age group (1) & 1 & 1 \\
\hline No disability - age group (2) & 1 & 1 \\
\hline No disability - age group (3) & 1 & 1 \\
\hline No disability - age group (4) & 1 & 1 \\
\hline No disability - age group (5) & 1 & 1 \\
\hline Disability - age group (1) & 1 & 1 \\
\hline Disability - age group (2) & 1.106 & 0.842 \\
\hline Disability - age group (3) & $1.542^{\star}$ & 1.087 \\
\hline Disability - age group (4) & 1.323 & 0.846 \\
\hline Disability - age group (5) & $1.916^{\star \star}$ & 1.454 \\
\hline
\end{tabular}

Note: A tailored version of the 2014 dataset was used for the analysis based on an agreement with the Care Quality Commission.

Source: Authors' calculations using the Adult Inpatient Survey, 2014.

Significance levels: ${ }^{\star} p<0.05,{ }^{\star \star} p<0.01,{ }^{\star \star \star} p<0.001$.

The fourth group of independent variables relate to broader dimensions of quality of care. Perceptions of the quantity and quality of nursing staff, and food services (specifically, whether there is a choice of food), are observed to have consistent, large and statistically significant associations with the probability of not receiving help with eating when it is needed during a hospital stay under all specifications of the model. Whilst these variables are influenced by resources, they are within the control of the hospital to some extent.

Finally, the results show that there are statistically significant differences between hospital trusts in the risk of inpatients experiencing poor or inconsistent support with eating, before any controls are introduced into the model (Figure 4a). These differences decline after each set of control variables is incorporated into the model, with a small number of significant differences remaining after controlling for inpatient characteristics, hospital-level deprivation and inpatient pathway (Figure 4b). No statistically significant differences between individual trusts and 


\section{Null model}
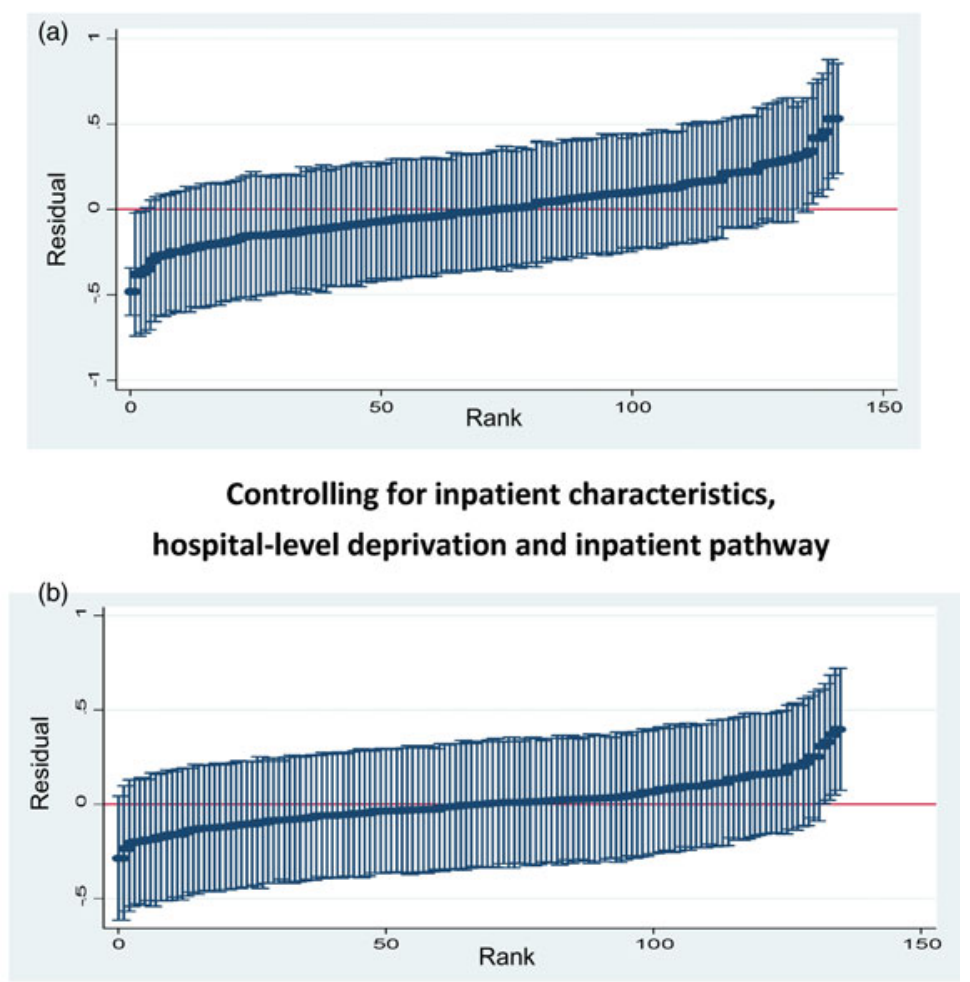

\section{Full multilevel model}

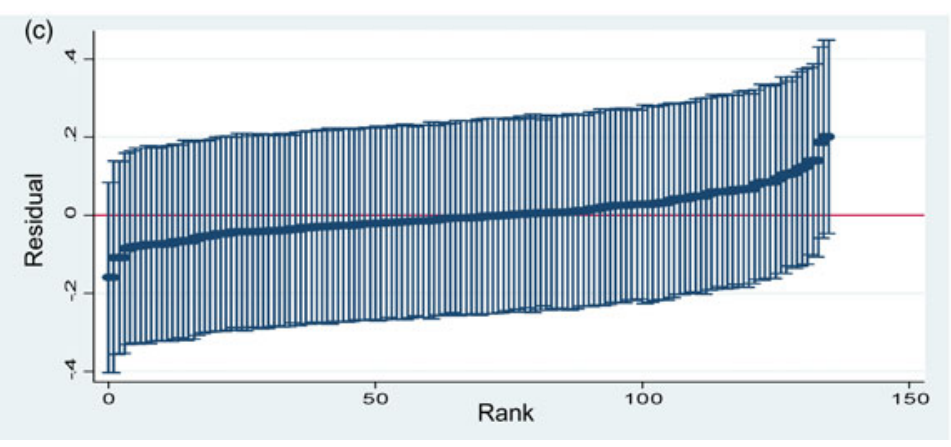

Figure 4. The association between individual hospital trust and inpatients' risk of experiencing poor or inconsistent support with eating (caterpillar plots, all respondents, 2014).

Notes: A tailored version of the 2014 dataset was used for the analysis based on an agreement with the Care Quality Commission. The caterpillar plots show the estimated residuals for hospital trusts, that is, the difference between the random intercept for each trust and the mean random intercept for all trusts. The residuals are calculated as the difference between the observed score and the score predicted by the regression equation.

Source: Authors' calculations using the Adult Inpatient Survey, 2014. 
the average trust - or between outcomes in trusts at the bottom and top ends of the distribution-are observed after the full set of controls are incorporated (Figure $4 \mathrm{c})^{5}$

\section{Limitations}

Cohort effects and the phenomenon of adaptive expectations are concerns when evaluating older people's self-reported experiences. Objective ward-level data on the numbers of nurses and/or quality are not available and we use AIS reported staffing of nursing care as a proxy. The interpretation of the effects of these variables is complex and endogeneity is a possibility. Response rates to the AIS are not as high as in some other surveys and whilst response rates are generally higher amongst older respondents, lower responses might be anticipated amongst older people who experience disabilities and/or dementia (Age UK, personal communication, 2013). Individuals who die during a hospital stay are not covered by the sampling frame. The new patient-level weights used in our calculations reflect a number of approximations (for further details, see Vizard and Burchardt, 2015), although we still consider them to be an improvement on using hospital trust weights or no weights at all. As a condition of access, specialist trusts have been grouped for much of the analysis, which has a small impact on our results, and the data on hospital-level deprivation does not cover specialist trusts. As a result, specialist trusts are not covered by the multilevel modelling results. Data restrictions also mean that it has not been possible to include ethnicity as a control within the regressions.

Despite these limitations, we believe our results make a distinct contribution, given the paucity of previous analysis of survey data on older people's experiences in hospital.

\section{Discussion, lessons and conclusions}

The policy developments discussed in this article mean that, in the English context, older people's rights to be treated with dignity and respect, and to support in meeting basic needs such as eating, are now formally recognised as fundamental requirements of hospital care. However, prior to our work in this area, nationally representative statistical evidence on older people's experience of these dimensions of hospital care in practice has been limited. Our detailed findings using the 2014 AIS suggest a widespread and systematic pattern of poor or inconsistent experiences of dignity and of support with eating during hospital stays amongst older people nationally. Unfortunately, trend data up to 2019 suggest that these problems are still prevalent.

The analysis suggests that inpatient experiences of poor and inconsistent standards of dignity and support with eating during hospital stays are not a marginal or isolated concern affecting a small number of isolated 'outlier' health-care providers, but are a general problem affecting a substantial proportion of older inpatients nationally. Looking at inequalities within the older population aged 65 or above, the prevalence of inconsistent and poor standards of care are higher amongst the 'oldest of the old' (individuals aged over 80), amongst individuals who experience a 
limiting long-standing illness or disability (such as cancer or a cardiovascular problem, a mental health problem or a learning difficulty, or a physical disability such as a mobility impairment, or hearing or sight loss) and for women. These risks are cumulative, and the highest prevalence of poor and inconsistent standards are observed amongst older women over 80 who experience a long-standing illness or disability.

There are a number of specific lessons from the analysis for future policy development. The small improvements around 2015 in the prevalence of poor and inconsistent experiences that we report in this article provide some ground for optimism that policy focus on dignity and support with eating during hospital stays can effect change, but renewed and sustained efforts are necessary if improvements are to continue. This is particularly important given that the context is one of mounting workforce and other pressures on health and care in England, as first austeritydriven resource constraints and now the COVID-19 pandemic have impacted the system. The multivariate findings show that the factors that predict unmet need for support with eating during hospital stays include gender, disability, route of admission, length of stay and number of wards. Nursing services and food delivery services stand out as key potential policy levers for the delivery of health care. Whilst these variables can be negatively affected by resource and workforce constraints, they are within the control of hospital trusts to a certain extent. For example, the Independent Review of NHS Hospital Food (Shelley, 2020) identifies good practice including flexible and more frequent meals; cleaning, de-cluttering and ensuring patients are ready; colour-coded trays to indicate which patients may need help; and support with dentures, swallowing, dexterity (including dealing with packaging and cutlery), confusion and motivation to eat.

The discussion provides several insights for health-care inspection and regulation. Official monitoring should recognise the possibility of adaptive expectations and should focus on inequalities within the older population. Monitoring should be based on narrow age-band disaggregation, with separate identification of the risks and vulnerabilities of the 'oldest of the old', and of the interaction of older age and other risk factors, including gender, disability and area deprivation. In addition, whilst we observe a wide variation in the raw percentages reporting poor and inconsistent inpatient experiences of dignity and support with eating between different hospitals in 2014, this percentage is too high in the vast majority of hospitals when compared to intuitive judgements about minimum acceptable standards. The application of a 'deviation from average' methodology for identifying poor performance is therefore likely to result in the under-identification of poor performance and an over-concentration on the need for quality improvement in a small number of outliers. We recommend instead the adoption of a 'minimum threshold' methodology, which we suggest is more in line with the concept of a fundamental standard as well as capability and rights-based approaches ( $c f$. Vizard and Burchardt, 2015).

Our analysis also has lessons and implications for the WHO's healthy ageing agenda and the goal of 'establishing health-care services that meet the needs of older people' by 2030. Conceptually, our analysis highlights the importance of dignity and support with eating for the characterisation of older people's functional ability, capabilities and wellbeing using the healthy ageing model. In policy 
terms, the study highlights the importance of dignity and support in meeting individual nutritional needs for the design and delivery of person-centred hospital service environments for older people by 2030. In addition, the discussion has drawn attention to the importance of national patient experience surveys as an informational base for developing new older-person-centred health-care indicators. The healthy ageing literature highlights that, in moving beyond a medical intervention model towards a model focusing on functional ability, capabilities and wellbeing in older age, there is a need to develop new measures and metrics that focus on outcomes that older people find meaningful, drawing on nationally representative social surveys (e.g. Michel and Sadana, 2017; Cesari et al., 2018; Marsman et al., 2018; Sadana and Banerjee, 2019). ${ }^{6}$ Our analysis highlights the potential importance of national patient surveys within this search for better measures and metrics, and as a source informational feedback and older people's voice within processes of health-care improvement and reform. We recommend that measures of older people's experience of dignity and support with eating during hospital stays, drawing on national patient surveys, are included within the portfolio of indicators that will be used to monitor the delivery of the WHO 2030 strategies and goals.

Looking forward, the WHO healthy ageing agenda will help to focus international attention on the importance of health and long-term care systems that maximise functional ability, capabilities and wellbeing in older age over the next decade. However, our empirical findings highlight the scale of the challenges involved in developing an adequate public action response to population ageing over the next decade and in ensuring that increasing life expectancy is matched by equivalent or greater increases in quality of life. Our analysis suggests that even within the context of a high-income country which benefits from a relatively well-resourced and universal public health-care system, and where policy development has accelerated in recent years, the delivery of integrated and olderpersoncentred health and care that maximises functional ability, capability and wellbeing in older age remains elusive.

Data. A tailored version of the 2014 Adult Inpatient Survey (AIS) was made available for the analysis based on an agreement with the Care Quality Commission (CQC). The 2004-2014 AIS datasets were made available by the UK Data Service. The CQC holds the copyright of AIS data. Neither the UK Data Archive nor the original data creators, depositors or copyright holders of the data bear any responsibility for the analysis.

Acknowledgements. We are extremely grateful to Karen Hallt and Stacey Smith (Care Quality Commission) who were critical in securing our access to and for providing the tailored secure version of the 2014 Adult Inpatient Survey dataset used in the analysis (this includes, inter alia, disability information, more detailed age information and a differential non-response weight). We would like to thank Ruth Isden and Nadia Kalam (Age UK) and Catherine Thompson (NHS England) for their commitment, advice, input and participation in relation to the project. We are grateful in addition for comments and feedback from Lesley Carter (Malnutrition Task Force) and the speakers and participants at a series of CASE/Age UK impact events and participants at the academic seminars and conferences where this material has been presented. The current article builds on our earlier research report, in relation to which we would like to thank Sheena MacCormick, Steve Sizmur and Chris Graham (Picker Institute Europe) for their support including in relation to access arrangements and provision of tailored datasets; and Steve Sizmur (Picker Institute) and Karl Ashworth (Office for National Statistics) for methodological input and advice on the development of the new set of patient weights. At the London School of 
Economics, we are extremely grateful to Ellie Suh who worked as Research Officer in the most recent round of the work, producing the 2014 igross weight and the updated time-series data tables. Responsibility for errors of fact or interpretation remains with the authors. UK Data Service dataset acknowledgements:

- Care Quality Commission, Picker Institute Europe (2011) Acute Trusts: Adult Inpatient Survey, 2010 (Data collection). UK Data Service, SN: 6821, doi:10.5255/UKDA-SN-6821-1.

- Care Quality Commission, Picker Institute Europe (2012) Acute Trusts: Adult Inpatient Survey, 2011 (Data collection). UK Data Service, SN: 7034, doi:10.5255/UKDA-SN-7034-1.

- Care Quality Commission, Picker Institute Europe (2013) Acute Trusts: Adult Inpatient Survey, 2012 (Data collection). UK Data Service, SN: 7273, doi:10.5255/UKDA-SN-7273-1.

- Care Quality Commission, Picker Institute Europe (2015) Acute Trusts: Adult Inpatient Survey, 2014 (Data collection). UK Data Service, SN: 7741, doi:10.5255/UKDA-SN-7741-1.

- Healthcare Commission, Picker Institute Europe (2006) Acute Trusts: Adult Inpatient Survey, 2004 (Data collection), 2nd Edn. UK Data Service, SN: 5167, doi:10.5255/UKDA-SN-5167-1.

- Healthcare Commission, Picker Institute Europe (2007) Acute Trusts: Adult Inpatient Survey, 2005 (Data collection). UK Data Service, SN: 5597, doi:10.5255/UKDA-SN-5597-1.

- Healthcare Commission, Picker Institute Europe (2007) Acute Trusts: Adult Inpatient Survey, 2006 (Data collection). UK Data Service, SN: 5628, doi:10.5255/UKDA-SN-5628-1.

- Healthcare Commission, Picker Institute Europe (2008) Acute Trusts: Adult Inpatient Survey, 2007 (Data collection), 2nd Edn. UK Data Service, SN: 5999, doi:10.5255/UKDA-SN-5999-1.

- Healthcare Commission, Picker Institute Europe (2009) Acute Trusts: Adult Inpatient Survey, 2008 (Data collection). UK Data Service, SN: 6256, doi:10.5255/UKDA-SN-6256-1.

Author contributions. Both authors have contributed substantially to the creation of this article.

Financial support. Funding for the 2014 inpatient experience analysis was provided by the LSE International Inequalities Institute and a LSE Knowledge Exchange Award. The analysis updates, deepens and extends analysis undertaken in an earlier project which was funded by an Economic and Social Research Council Secondary Data Analysis award (ES/K004018/1). Age UK and partners who contributed to a series of workshops have also provided time and input into the knowledge exchange component of the project.

Conflict of interest. The authors declare no conflicts of interest.

Ethical standards. The research for this article did not involve human subjects.

\section{Notes}

1 We acknowledge that the underlying causes of malnutrition are complex and multifaceted and include socio-economic drivers and disease-related factors as well as functional dependency. However, given the high prevalence of ADL limitations among older people on admission to hospital - as well as evidence of ADL functional decline among some older people during hospital stays (e.g. Covinsky, 2003) - outcomes for older adults who are impacted by ADL limitations may be modified and improved through the provision of appropriate support (O'Shea, 2017).

2 The OECD's new Patient-Reported Indicator Survey (PaRIS) aims to promote the systematic use of patient-reported data within health-care systems and includes measures of both patient-reported outcomes (proms) and patient-reported experiences (prems). For further discussion, see Fujisawa and Klazinga (2017) and OECD $(2019 a, 2019 b, 2019 c$, nd).

3 Findings from other previous studies using the AIS are reviewed in Vizard and Burchardt (2015). The issue of subjectivity and the possibility of systematic differences in the way that different population subgroups respond to user experience surveys raises important questions regarding the validity, reliability and response bias which can affect the comparability of this data and hence its role in monitoring health-care outcomes. The issues are not limited to older people since systematic differences in the way that other population sub-groups respond to these surveys (e.g. by gender or ethnicity) might also occur. The issue 
of cross-country comparability has also been discussed in the literature. For further discussion and the question of methodological responses to these issues (e.g. arguments for and against controlling by case mix), see Larson et al. (2019), Paddison et al. (2012) and Ahmed et al. (2014).

4 Further methodological background and sensitivity testing of the new weights is provided in Vizard and Burchardt (2015).

5 Since data on hospital-level deprivation is not available for specialist trusts, sensitivity testing using a fixed-effects version of the model which includes specialist trusts but excludes hospital-level deprivation as an independent variable has also been undertaken. The fixed-effects model including all other controls and all respondents points towards five trusts being identified as having odds ratios that are significantly higher. 6 The literature and a recent workshop highlight the need for new metrics and measures of intrinsic capacity, functional ability and enabling environments over the lifecourse. The WHO International Classification of Functioning, Disability and Health, and the WHO Model Disability Survey, which captures aspects of the enabling environment, including family and social support, personal assistance, assistive products for self-care, mobility etc., have been highlighted as potential starting points for this exercise. The potential of national social survey data, especially longitudinal data, has also been emphasised. For further discussion, see Sadana and Banerjee (2019), Michel and Sadana (2017), Cesari et al. (2018) and Marsman et al. (2018).

\section{References}

Age UK (2010) Still Hungry to Be Heard: The Scandal of People in Later Life Becoming Malnourished in Hospital. Available at http://www.ageuk.org.uk/Documents/EN-GB/ID9489\%20HTBH\%20Report\% 2028ppA4.pdf?dtrk=true.

Ahmed F, Burt J and Roland M (2014) Measuring patient experience: concepts and methods. The Patient - Patient-Centred Outcomes Research 7, 235-241.

Black K and Dobbs D (2014) Community-dwelling older adults' perceptions of dignity: core meanings, challenges, supports and opportunities. Ageing \& Society 34, 1292-1313.

Bleich S, Ozaltin E and Murray C (2009) How does satisfaction with the healthcare system relate to patient experience? Bulletin of the World Health Organization 87, 271-278.

Breheny M, Stephens C, Henricksen A, Stevenson B, Carter K and Alpass F (2016) Measuring living standards of older people using Sen's Capability Approach: development and validation of the LSCAPE-24 (Living Standards Capabilities for Elders) and LSCAPE-6. Ageing \& Society 36, 307-332.

British Association of Enteral and Parenteral Nutrition (BAPEN) (2018a) Introduction to Malnutrition. Available at https://www.bapen.org.uk/malnutrition-undernutrition/introduction-tomalnutrition? showall $=\&$ start $=4$.

British Association of Enteral and Parenteral Nutrition (BAPEN) (2018b) Managing Malnutrition to Save Lives and Save Money. Available at https://www.bapen.org.uk/pdfs/reports/mag/managing-malnutrition.pdf.

British Association of Enteral and Parenteral Nutrition (BAPEN) (nd) Nutritional Care Tool. Available at https://www.data.bapen.org.uk/data-collection/operational-definitions.

Burchardt T (2004) Capabilities and disability: the capabilities framework and the social model of disability. Disability and Society 19, 735-751.

Burchardt T and Vizard P (2011) Operationalizing the capability approach as a basis for equality and human rights monitoring in twenty-first-century Britain. Journal of Human Development and Capabilities 12, 91-119.

Burchardt T and Vizard P (2014) Using the capability approach to evaluate health and care for individuals and groups in England. In Ibrahim S and Tiwari M (eds), The Capability Approach from Theory to Practice. Palgrave.

Calnan M, Tadd W, Calnan S, Hillman A, Read S and Bayer A (2013) I often worry about the older person being in that system: exploring the key influences on the provision of dignified care for older people in acute hospitals. Ageing \& Society 33, 465-485.

Care Quality Commission (CQC) (2011) Dignity and Nutrition Inspection Programme-National Overview. Available at http://www.cqc.org.uk/sites/default/files/media/documents/20111007_dignity_and_ nutrition_inspection_report_final_update.pdf. 
Care Quality Commission (CQC) (2013a) Time to Listen in NHS Hospitals - Dignity and Nutrition Inspection Programme 2012. Available at http://www.cqc.org.uk/sites/default/files/media/documents/ time_to_listen_-_nhs_hospitals_main_report_tag.pdf.

Care Quality Commission (CQC) (2013b) Intelligent Monitoring - NHS Acute Hospitals Indicators and Methodology. Available at http://www.cqc.org.uk/sites/default/files/media/documents/20131119_intelligent_monitoring_indicators_and_methodology_v12_for_publication.pdf.

Care Quality Commission (CQC) (2013c) Intelligent Monitoring-NHS Acute Hospitals Statistical Methodology. Available at http://www.cqc.org.uk/sites/default/files/media/documents/20131119_intelligent_monitoring_statistical_methodology_with_esr_sus_and_overdispersion_changes_for_publication. pdf.

Care Quality Commission (CQC) (2013d) Inpatient Survey 2012: National Summary. Available at http:// www.cqc.org.uk/public/reports-surveys-and-reviews/surveys/inpatient-survey-2012.

Care Quality Commission (CQC) (2013e) Inpatient Survey 2012: Historical Comparisons. Available at http://www.cqc.org.uk/public/reports-surveys-and-reviews/surveys/inpatient-survey-2012.

Care Quality Commission (CQC) (2013f) Inpatient Survey 2012: Technical Document. Available at http:// www.cqc.org.uk/public/reports-surveys-and-reviews/surveys/inpatient-survey-2012.

Care Quality Commission (CQC) (2013g) National Summary included with the 2012 Adult Inpatient Survey dataset UK Data Archive Study Number 7273 - Acute Trusts: Adult Inpatient Survey, 2012

Care Quality Commission (CQC) (2014) Survey of Adult Inpatients 2013: Full Results with 2012 Comparisons. Available at www.nhssurveys.org.

Care Quality Commission (CQC) (2017) State of Care in NHS Acute Hospitals 2014-2016: Findings from the NHS Acute Comprehensive Inspections. Available at https://www.cqc.org.uk/sites/default/files/ 20170302b_stateofhospitals_web.pdf.

Care Quality Commission (CQC) (2018) Beyond Barriers: How Older People Move Between Health and Care in England. Available at https://www.cqc.org.uk/sites/default/files/20180702_beyond_barriers.pdf.

Care Quality Commission (CQC) (2019) State of Care 2019. Available at https://www.cqc.org.uk/sites/ default/files/20191015b_stateofcare1819_fullreport.pdf.

Care Quality Commission (CQC) (2020) Adult Inpatient Survey 2019: National Tables. Available at https:// www.cqc.org.uk/publications/surveys/adult-inpatient-survey-2019.

Care Quality Commission (CQC) (nd-a) Regulation 10: Dignity and Respect. Available at https://www.cqc. org.uk/guidance-providers/regulations-enforcement/regulation-10-dignity-respect\#guidance.

Care Quality Commission (CQC) (nd-b) Regulation 14: Meeting Nutritional and Hydrational Needs. Available at https://www.cqc.org.uk/guidance-providers/regulations-enforcement/regulation-14-meetingnutritional-hydration-needs\#full-regulation.

Cesari M, Carvalho IA, Thiyagarajan JA, Cooper C, Martin F, Reginster JY, Vellas B and Beard JR (2018) Evidence for the domains supporting the construct of intrinsic capacity. Journals of Gerontology: Biological Sciences and Medical Sciences 73A, 1653-1660.

Claassen R (2015) Human dignity in the capability approach. In Duwell M, Braarvig J, Brownsword R and Mieth D (eds). Cambridge Handbook of Human Dignity. Cambridge: Cambridge University Press, pp. 240-249.

Coast J (2014) Strategies for the economic evaluation of end-of-life care: making a case for the capability approach. Expert Review of Pharmacoeconomics and Outcomes Research 14, 473-482.

Coast J, Flynn T, Natarajan L, Sproston K, Lewis J, Louviere JJ and Peters TJ (2008) Valuing the ICECAP capability index for older people. Social Science and Medicine 67, 874-882.

Coast J, Kinghorn P and Mitchell P (2015) The development of capability measures in health economics: opportunities, challenges and progress. The Patient-Patient-Centred Outcomes Research 8, 119-126.

Coast J, Bailey C and Kinghorn P (2018) Patient centred outcome measurement in health economics: beyond EQ-5D and the Quality-Adjusted Life-Year - where are we now? Annals of Palliative Medicine 7(Supplement 3), S249-S252. doi: 10.21037/apm.2018.03.18.

Covinsky K, Palmer R, Fortinsky RH, Counsell SR, Stewart AL, Kresevic D, Burant CJ and Landefeld CS (2003) Loss of independence in activities of daily living in older adults hospitalized with medical illnesses: increased vulnerability with age. Journal of the American Geriatrics Society 51, 451-458.

Department of Health (2013a) Hard Truths: The Journey to Putting Patients First, Vols 1 and 2. London: The Stationary Office. Available at https://www.gov.uk/government/publications/mid-staffordshire-nhs$\mathrm{ft}$-public-inquiry-government-response. 
Department of Health (2013b) Mid Staffordshire NHS Foundation Trust Public Inquiry: Government Response. Available at http://francisresponse.dh.gov.uk/list-of-responses-to-recommendations/.

Department of Health (2013c) Putting Patients First: Government Publishes Response to Francis Report (Press release). Available at https://www.gov.uk/government/news/putting-patients-first-governmentpublishes-response-to-francis-report.

Department of Health (2013d) Patients First and Foremost: The Initial Government Response to the Francis Report. London: The Stationary Office. Available at https://assets.publishing.service.gov.uk/government/ uploads/system/uploads/attachment_data/file/170701/Patients_First_and_Foremost.pdf.

Department of Health (2013e) The Government's Further Response to Robert Francis QC's Report on the Mid Staffordshire NHS Foundation Trust Public Inquiry. Available at https://www.gov.uk/government/ publications/mid-staffordshire-nhs-ft-public-inquiry-government-response.

Department of Health and Social Care (2015) The NHS Constitution for England. Available at https:// www.gov.uk/government/publications/the-nhs-constitution-for-england/the-nhs-constitution-for-england\# patients-and-the-public-your-rights-and-the-nhs-pledges-to-you.

Entwistle V and Watt I (2013) Treating patients as persons: a capabilities approach to support delivery of person-centered care. American Journal of Bioethics 13, 8, 29-39.

Equality and Human Rights Commission (EHRC) (2015) Is Britain Fairer Evidence Series, Domain 8: Health. Available at https://webarchive.nationalarchives.gov.uk/20170804152334/https://www.equalityhumanrights.com/en/britain-fairer/britain-fairer-report/supporting-evidence/health-domain.

Fujisawa $\mathbf{R}$ and Klazinga $\mathbf{N}$ (2017) Measuring patient experiences (PREMs): progress made by the OECD and its member countries 2006-2015. Organisation for Economic Co-operation and Development, Paris, OECD Health Working Papers No. 102.

Gallagher A, Li S, Wainwright P, Jones I and Lee D (2008) Dignity in the care of older people - a review of the theoretical and empirical literature. BMC Nursing 7, 11.

Garratt A, Solheim E and Danielsen K (2008) National and Cross-national Surveys of Patient Experiences: A Structured Review. Available at http://www.oecd.org/els/health-systems/39493930.pdf.

Gopinath M (2018) Thinking about later life: insights from the capability approach. Ageing International 43, 254-264.

Grewal I, Lewis J, Flynn T, Brown J, Bond J and Coast J (2006) Developing attributes for a generic quality of life measure for older people: preferences or capabilities? Social Science and Medicine 62, 1891-1901.

Health and Social Care Information Centre (2015a) Hospital Episode Statistics Admitted Patient Care, England 2014-15. Available at https:/digital.nhs.uk/data-and-information/publications/statistical/hospital-admitted-patient-care-activity/hospital-episode-statistics-admitted-patient-care-england-2014-15.

Health and Social Care Information Centre (2015b) Hospital Episode Statistics Admitted Patient Care, England 2014-15: Excel Spreadsheet on Episodes by Organisation that Provided the Admitted Patient Care. Available at https://digital.nhs.uk/data-and-information/publications/statistical/hospital-admittedpatient-care-activity/hospital-episode-statistics-admitted-patient-care-england-2014-15.

Health and Social Care Information Centre (2016) Provider Spells Split by Deprivation Level, July 2014June 2015. Available at https://indicators.hscic.gov.uk/webview/.

Healthcare Commission (2005) Variations in the Experiences of Patients in England: Analysis of the Healthcare Commission's 2003/2004 National Surveys of Patients. Available at http://archive.cqc.org.uk/ _db/_documents/04021207.pdf.

Healthcare Commission (2006) Variations in the Experiences of Patients in England: Analysis of the Healthcare Commission's 2004/2005. National Surveys of Patients. Available at http://archive.cqc.org. uk/_db/_documents/Surveys_Variations_Report1.pdf.

Health Service Ombudsman (2011) Care and Compassion: Report of the Health Services Ombudsman on 10 Investigations into NHS Care of Older People. London: The Stationary Office. Available at http://www. ombudsman.org.uk/care-and-compassion/home.

HM Government (2012) Caring for Our Future: Reforming Care and Support. London: The Stationary Office. Available at https://www.gov.uk/government/publications/caring-for-our-future-reforming-careand-support.

Ipsos MORI (2008) Frontiers of Performance in the NHS II. Available at http://www.ipsos-mori.com/ Assets/Docs/Frontiers\%20of\%20health\%20report\%20(web).pdf. 
Johnston B, Flemming K, Narayanasamy MJ, Coole C and Hardy B (2017) Patient reported outcome measures for measuring dignity in palliative and end of life care: a scoping review. BMC Health Services Research 17, 574.

Joint Committee on Human Rights (2007) The Human Rights of Older People in Healthcare, Eighteenth Report of Session 2006-07. London: The Stationary Office. Available at www.publications.parliament.uk/ pa/jt200607/jtselect/jtrights/156/156i.pdf.

Keogh B (2013) Review into the Quality of Care and Treatment Provided by 14 Hospital Trusts in England: Overview Report. Available at https://www.nhs.uk/nhsengland/bruce-keogh-review/documents/outcomes/keogh-review-final-report.pdf.

Larson E, Sharma J, Bohren M and Tuncalp O (2019) When the patient is the expert: measuring patient experience and satisfaction with care. Bulletin of the World Health Organization 97, 563-569.

Lloyd L, Calnan M, Cameron A, Seymour J and Smith R (2014) Identity in the fourth age: perseverance, adaptation and maintaining dignity. Ageing \& Society 34, 1-19.

Lloyd L, Calnan M, Cameron A, Seymour J, Smith R and White K (2017) Older people's perspectives on dignity: the benefits and challenges of a qualitative longitudinal approach to researching experiences of later life. International Journal of Social Research Methodology 20(6), 647 -658.

Malnutrition Taskforce (nd) Hospitals. Available at https://www.malnutritiontaskforce.org.uk/professionals/hospitals.

Marsman D, Belsky DW, Gregori D, Johnson MA, Low Dog T, Meydani S, Pigat S, Sadana R, Shao A and Griffiths JC (2018) Healthy ageing: the natural consequences of good nutrition - a conference report. European Journal of Nutrition 57, supplement 2, 15-34.

Michel J and Sadana R (2017) Health ageing concepts and measures. Journal of the American Medical Directors Association 18, 460-464.

Mid Staffordshire NHS Foundation Trust Public Inquiry (2013a) Robert Francis QC: Press Statement. Available at http://www.midstaffspublicinquiry.com/sites/default/files/report/Chairman\%27s\%20statement. pdf.

Mid Staffordshire NHS Foundation Trust Public Inquiry (2013b) Final Report. London: The Stationary Office. Available at http://www.midstaffspublicinquiry.com/.

Mitchell P, Roberts T and Coast J (2017a) Applications of the capability approach in the health field: a literature review. Social Indicators Research 133, 345-371.

Mitchell PM, Venkatapuram S, Richardson J, Lezzi A and Coast J (2017b) Are quality-adjusted life years a good proxy measure of individual capabilities? PharmacoEconomics 35, 637-646.

Murphy J (2019) Malnutrition: A Significant Threat to Our Health as We Age. Available at https://www.bgs. org.uk/blog/malnutrition-a-significant-threat-to-our-health-as-we-age.

National Health Service (NHS) (2014) Five Year Forward View. Available at https://www.england.nhs.uk/ wp-content/uploads/2014/10/5yfv-web.pdf.

National Institute for Health and Care Excellence (NICE) (2012) NICE Clinical Guidelines CG138. Patient Experience in Adult NHS Services: Improving the Experience of Care for People Using Adult NHS Services. Available at http://publications.nice.org.uk/patient-experience-in-adult-nhs-servicesimproving-the-experience-of-care-for-people-using-adult-cg138/quality-statements.

National Institute for Health and Care Excellence (NICE) (2014) Safe Staffing for Nursing in Adult Inpatient Wards in Acute Hospitals: NICE Safe Staffing Guideline. Available at https://www.nice.org. uk/Guidance/SG1.

NHS England (2015) Guidance - Commissioning Excellent Nutrition and Hydration 2015-2018. Available at https://www.england.nhs.uk/wp-content/uploads/2015/10/nut-hyd-guid.pdf.

NHS England (2019) Long-term Plan. Available at https://www.longtermplan.nhs.uk/.

Nussbaum M (2000) Women and Human Development: The Capabilities Approach. Cambridge: Cambridge University Press.

Organisation for Economic Co-operation and Development (OECD) (2019a) Health at a Glance 2019: OECD Indicators, chap. 2. Available at https://www.oecd-ilibrary.org/sites/4bbba455-en/index.html? itemId=/content/component/4bbba455-en\&mimeType=text $/ \mathrm{html}$.

Organisation for Economic Co-operation and Development (OECD) (2019b) Putting People at the Centre of Healthcare. PaRIS Survey of Patients with Chronic Conditions. Available at http://www.oecd. org/health/health-systems/PaRIS-survey-Patients-with-Chronic-Conditions-June-2019.pdf. 
Organisation for Economic Co-operation and Development (OECD) (2019c) Definitions for Quality of Care Indicators. Available at https://www.oecd.org/els/health-systems/Definitions-of-Health-Care-QualityIndicators.pdf.

Organisation for Economic Co-operation and Development (OECD) (nd) Patient-Reported Indicators Surveys (PaRIS) Mini Website. Available at https://www.oecd.org/health/paris.htm.

O'Shea E, Trawley S, Manning E, Barrett A, Browne V and Timmons S (2017) Malnutrition in hospitalised older adults: a multicentre observational study of prevalence, associations and outcomes. Journal of Nutrition, Health \& Aging 21, 830-836.

Ota K, Maeda J, Gallagher A, Yahiro M, Niimi Y, Chan M and Matsuda M (2019) Development of the Inpatient Dignity Scale through studies in Japan, Singapore, and the United Kingdom. Asian Nursing Research 13, 76-85.

Paddison C, Elliott M, Parker R, Staetsky L, Lyratzopoulos G, Campbell JL and Roland M (2012) Should measures of patient experience in primary care be adjusted for case mix? Evidence from the English General Practice Patient Survey. BMJ Quality and Safety 21, 634-640.

Patients Association (2011) We've Been Listening, Have You Been Learning? Available at http://patientsassociation.com/Portals/0/Public/Files/Research\%20Publications/We've\%20been\%20listening,\%20have\% 20you\%20been\%20learning.pdf.

Prah Ruger J (2010) Health capability: conceptualization and operationalization. American Journal of Public Health 100, 41-49.

Prah Ruger J and Mitra S (2015) Health, disability and the capability approach: an introduction. Journal of Human Development and Capabilities 16, 473-482.

Roberts H, Lim S, Cox N and Ibrahim K (2019) The challenge of managing undernutrition in older people with frailty. Nutrients 11, 808.

Robeyns I (2017) Wellbeing, Freedom and Justice: The Capability Approach Re-examined. Cambridge: Open Book Publishers.

Royal College of Nursing (2008) Dignity: At the Heart of Everything We Do. Available at https://www.dignityincare.org.uk/Resources/Type/RCN-Dignity-at-the-Heart-of-everything-we-do/.

Sadana R and Banerjee A (2019) Metrics and evidence for healthy ageing. Bulletin of the World Health Organization 97, 792-792A. doi: http://dx.doi.org/10.2471/BLT.19.246801.

Sen A (1983) Poor, relatively speaking. Oxford Economic Papers 35, 153-169.

Shelley P (2020) Report of the Independent Review of NHS Hospital Food. Department of Health and Social Care. Available at https://www.gov.uk/government/publications/independent-review-of-nhs-hospital-food.

Simon J, Anand P, Gray A, Rugkåsa J, Yeeles K and Burns T (2013) Operationalising the capability approach for outcome measurement in mental health research. Social Science and Medicine 98, 187-196.

Sizmur S (2011) Multilevel Analysis of Patient Experience. Oxford: Picker Institute. Available at http://www. pickereurope.org/wp-content/uploads/2014/10/Multi-level-analysis-of-inpatient-experience.pdf.

Sizmur S and Korner K (2013) Equal rights, equal respect: an examination of differential inpatient experience in the NHS. Diversity and Equality in Health and Care 10, 237-247.

Stephens C and Breheny M (2019) Healthy Ageing: A Capability Approach to Inclusive Policy and Practice. New York, NY: Routledge.

Tadd W, Hillman A, Calnan S, Calnan M, Bayer T and Read S (2011) Dignity in Practice: An Exploration of the Care of Older Adults in Acute NHS Trusts. Available at http://www.netscc.ac.uk/hsdr/files/project/ SDO_ES_08-1819-218_V01.pdf.

Tauber-Gilmore M, Addis G, Zahran Z, Black S, Baille L, Procter S and Norton C (2018) The views of older people and health professionals about dignity in acute hospital care. Journal of Clinical Nursing 27, 223-234.

Venkatapuram S, Ehni H and Saxena A (2017) Equity and healthy ageing. Bulletin of the World Health Organization 95, 791-792. http://dx.doi.org/10.2471/BLT.16.187609.

Vizard P and Burchardt T (2015) Older People's Experiences of Dignity and Nutrition During Hospital Stays: Secondary Data Analysis Using the Adult Inpatient Survey (CASE Report 91). Available at http://sticerd.lse.ac.uk/dps/case/cr/casereport91.pdf.

Vizard $\mathbf{P}$ and Obolenskaya $\mathbf{P}$ with Hughes $\mathbf{J}$, Treebhoohun $\mathbf{K}$ and Wainwright $\mathbf{I}$ (forthcoming) The Conservative Governments' Record on Health from May 2015 to Pre-COVID 2020: Policies, Spending and Outcomes (SPDO Research Paper). 
Woolhead G, Calnan M, Dieppe P and Tadd W (2004) Dignity in older age: what do older people in the United Kingdom think? Age and Ageing 33, 165-170.

World Health Organization (WHO) (2015a) World Report on Ageing and Health, chap. 2, pp. 25-42 and chap. 5, pp. 127-155. Geneva: WHO. Available at https://apps.who.int/iris/bitstream/handle/10665/ 186463/9789240694811_eng.pdf;jsessionid=2F87CF55EEAE266136AD33F421152E18? sequence=1.

World Health Organization (WHO) (2015b) Framework on Integrated, Person Centred Health Services. Geneva: WHO. Available at http://apps.who.int/gb/ebwha/pdf_files/WHA69/A69_39-en.pdf?ua=18ua=1.

World Health Organization (WHO) (2020) Healthy Ageing Mini Website. Geneva: WHO. Available at https://www.who.int/ageing/healthy-ageing/en/.

World Health Organization (WHO) (nd) Healthy Ageing and the Sustainable Development Goals Mini Website. Geneva: WHO. Available at https://www.who.int/ageing/sdgs/en/.

Zaidi A (2011) Exclusion from Material Resources Among Older People in EU Countries: New Evidence on Poverty and Capability Deprivation. Vienna: European Centre for Social Welfare Policy and Research.

Zavaleta D (2007) The ability to go about without shame: a proposal for internationally comparable indicators of shame and humiliation. Department of International Development, University of Oxford, Oxford, OPHI Working Paper 03. Available at https://ophi.org.uk/working-paper-number-03/.

Cite this article: Vizard P, Burchardt T (2021). Older people's experiences of dignity and support with eating during hospital stays: analytical framework, policies and outcomes. Ageing \& Society 1-35. https:// doi.org/10.1017/S0144686X21000568 